\title{
Assessment of microvascular and metabolic responses in the skin
}

\author{
Fredrik Iredahl
}

Department of Clinical and Experimental Medicine

Faculty of Medicine and Health Sciences

Linköping University

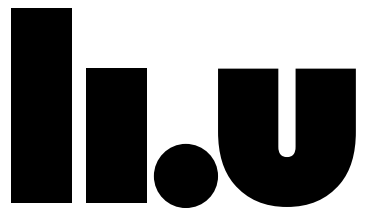

LINKÖPING UNIVERSITY 
Assessment of microvascular and metabolic responses in the skin

(C) Fredrik Iredahl, 2016

fredrik.iredahl@liu.se

Previously published material has been reprinted with permission from the respective copyright holder.

Cover design by Simon Farnebo and Per Lagman.

ISBN: 978-91-7685-702-1

ISSN: 0345-0082

Printed in Linköping, Sweden 2016

Liu-Tryck AB 
"There's a way to do it better... find it."

Thomas A. Edison, inventor 


\section{Supervisor}

Erik Tesselaar, Associate Professor

Department of Clinical and Experimental Medicine, Division of Clinical Sciences

Faculty of Medicine and Health Sciences, Linköping University

\section{Assistant supervisors}

Folke Sjöberg, Professor

Department of Clinical and Experimental Medicine, Division of Clinical Sciences

Faculty of Medicine and Health Sciences, Linköping University

Simon Farnebo, Associate Professor

Department of Clinical and Experimental Medicine, Division of Clinical Sciences

Faculty of Medicine and Health Sciences, Linköping University

\section{Opponent}

Sven Andersson, Associate Professor

Department of Clinical Sciences, Division of Medicine, Lund

Faculty of Medicine, Lund University

\section{Faculty board}

Karl-Erik Magnusson, Professor

Department of Clinical and Experimental Medicine, Division of Medical Microbiology

Linköping University

Per-Anders Jansson, Professor

Department of Molecular and Clinical Medicine, Division of Medicine, Sahlgrenska Academy

University of Gothenburg

Neil Lagali, Associate Professor

Department of Clinical and Experimental Medicine, Ophthalmology

Linköping University 


\section{Abstract}

The general aim of this project was to develop experimental in vivo models that allow for minimally invasive investigations of responses in the skin to microvascular and metabolic provocations. The cutaneous microvasculature has emerged as a valuable model and been proposed to mirror the microcirculation in other organs. Dysfunction in the cutaneous microcirculation has thus been linked to systemic diseases such as hypertension and diabetes mellitus. Models for investigating skin responses could facilitate the understanding of pathophysiological mechanisms as well as effects of drugs.

In the first study, three optical measurement techniques (laser Doppler flowmetry (LDF), laser speckle contrast imaging (LSCI) and tissue viability imaging (TiVi)) were compared against each other and showed differences in their ability to detect microvascular responses to provocations in the skin. TiVi was found more sensitive for measurement of noradrenaline-induced vasoconstriction, while LSCI was more sensitive for measurement of vascular occlusion. In the second study, microvascular responses in the skin to iontophoresis of vasoactive drugs were found to depend on the drug delivery protocol. Perfusion half-life was defined and used to describe the decay in the microvascular response to a drug after iontophoresis. In the third study, the role of nitric oxide (NO) was assessed during iontophoresis of insulin. The results showed a NO-dependent vasodilation in the skin by insulin. In the fourth study the vasoactive and metabolic effects of insulin were studied after both local and endogenous administration. Local delivery of insulin increased skin blood flow, paralleled by increased skin concentrations of interstitial pyruvate and lactate, although no change in glucose concentration was observed. An oral glucose load resulted in an increased insulin concentration in the skin paralleled by an increase in blood flow, as measured using the microdialysis urea clearance technique, although no changes in perfusion was measured by LSCI.

The thesis concludes that when studying skin microvascular responses, the choice of measurement technique and the drug delivery protocol has an impact on the measurement results, and should therefore be carefully considered. The thesis also concludes that insulin has metabolic and vasodilatory effects in the skin both when administered locally and as an endogenous response to an oral glucose load. The vasodilatory effect of insulin in the skin is mediated by nitric oxide. 


\section{Populärvetenskaplig sammanfattning}

Människans hud är fascinerande ur många hänseenden. Den skyddar oss bland annat mot yttre angrepp från kemikalier och bakterier, producerar D-vitamin i solljus, är rikligt fylld med känselreceptorer liksom har stor estetisk betydelse. Huden består av flera lager av celler och dessa får sin näring och syre genom blodomloppet. Blodet $\mathrm{i}$ våra blodkärl pumpas runt av hjärtat - ut i stora kroppspulsådern för att sedan $\mathrm{i}$ allt mindre blodkärl pumpas mot de minsta blodkärlen där leverans av näring och syre sker. Idag drabbas många människor av hjärt- och kärlsjukdomar. En känd riskfaktor för hjärt- och kärlsjukdomar är typ 2-diabetes. Denna vanligt förekommande sjukdom innebär att kroppen inte svarar normalt på hormonet insulin. I denna avhandling har vi studerat vilka mekanismer och vilken betydelse insulin har i huden. Det är i huvudsak de minsta blodkärlens funktion i huden som har studerats. Förutom betydelsen av insulin i har vi har också undersökt hur vi kan studera dessa minsta blodkärl med modern teknik och hur vi kan tillvarata mätresultaten.

Avhandlingen består av fyra delarbeten där underarmens hud studerats på friska forskningspersoner. I det första delarbetet jämfördes tre mättekniker mot varandra genom att huden utsattes för lokal uppvärmning, uttömning och återfyllnad av blodet, samt direktleverans av läkemedel som signalerar till blodkärlen att öppna liksom att dra ihop sig. Resultaten visar på mätteknikernas styrkor och svagheter, vilka bör tillvaratas när huden studeras. I det andra delarbetet levererades läkemedel med en teknik som benämns jontofores. Jontofores låter läkemedel, utan nålstick, transporteras med hjälp av en elektrisk ström genom huden. Resultatet visar att beroende av i vilken takt som läkemedel ges erhålls varierande svar i hudens minsta blodkärl, likaså ändras svaret om läkemedlet ges vid upprepade tillfällen på samma ställe på huden. I det tredje delarbetet studerades vilken roll kväveoxid spelar för insulin i huden. Kväveoxid är en molekyl som får blodkärlen att slappna av och resultatet visar på att insulin är beroende av kväveoxid för att öppna de minsta blodkärlen. I det sista delarbetet användes en teknik som benämns mikrodialys. Mikrodialys utgår från en tunn plastslang som förs in i huden och med hjälp av mycket små hål låter ämnen vandra in och ut genom plastslangen. Genom mikrodialys kunde vi studera hur insulin verkar i huden både avseende påverkan på de minsta blodkärlen, men också hur insulin påverkar sockeromsättningen i huden. Insulin verkade både genom att öka blodflödet och genom att öka förbränningen av socker.

Resultaten från avhandlingen är av betydelse när framtida studier ska genomföras för att vidare förstå hudens fulla funktion och betydelse. Resultaten har också potential att förbättra framtida studier där huden användas för att studera förändringar i sockeromsättningen och blodkärlen vid hjärt- och kärlsjukdomar liksom vid diabetes. 


\section{List of original papers}

The present thesis is a summary and discussion of the results presented in the following papers, which will be referred to by their roman numerals:

I. F. Iredahl, A. Löfberg, F. Sjöberg, S. Farnebo, E. Tesselaar

Non-invasive measurement of microvascular responses in the skin during pharmacological and physiological provocations

PLoS ONE 10(8):e0133760. doi:10.1371/journal.pone.0133760, 2015

II. F. Iredahl, V. Sadda, L. Ward, J. Hackethal, S. Farnebo, E. Tesselaar, F. Sjöberg Modeling perfusion dynamics in the skin during iontophoresis of vasoactive drugs using single-pulse and multiple-pulse protocols

Microcirculation 22: 446-453, 2015.

III. F. Iredahl, E. Tesselaar, S. Sarker, S. Farnebo, F. Sjöberg

The microvascular response to transdermal iontophoresis of insulin is mediated by nitric oxide

Microcirculation 20: 717-723, 2013.

IV. F. Iredahl, A. Högstedt, J. Henricson, F. Sjöberg, E. Tesselaar, S. Farnebo

Skin glucose metabolism and microvascular blood flow during local insulin delivery and after an oral glucose load

Accepted for publication in Microcirculation 2016 


\section{Abbreviations}

\begin{tabular}{|c|c|}
\hline $\mathrm{ACh}$ & acetylcholine \\
\hline $\mathrm{AChE}$ & acetylcholinesterase \\
\hline ANOVA & analysis of variance \\
\hline $\mathrm{AU}$ & arbitrary units \\
\hline BMI & body mass index \\
\hline $\mathrm{CV}$ & coefficient of variation \\
\hline EDHF & endothelium-derived hyperpolarisation factor \\
\hline EMLA & eutectic mixture of local anaesthetics \\
\hline ET-1 & endothelin-1 \\
\hline HOMA & homeostasis model assessment \\
\hline In vitro & Latin: within the glass. Experimental testing outside an organism. \\
\hline In vivo & Latin: within the living. Experimental testing inside an organism. \\
\hline LDF & laser Doppler flowmetry \\
\hline L-NAME & N-nitro-L-arginine methyl ester \\
\hline LSCI & laser speckle contrast imaging \\
\hline $\mathrm{MCh}$ & methacholine \\
\hline NA & noradrenaline \\
\hline $\mathrm{NADH}$ & nicotinamide adenine dinucleotide \\
\hline NO & nitric oxide \\
\hline NOS & nitric oxide synthase \\
\hline OGTT & oral glucose tolerance test \\
\hline PBS & phosphate-buffered saline \\
\hline PORH & post occlusive reactive hyperaemia \\
\hline PU & perfusions units \\
\hline $\mathrm{RBC}$ & red blood cell \\
\hline $\mathrm{SD}$ & standard deviation \\
\hline SEM & standard error of the mean \\
\hline SNP & sodium nitroprusside \\
\hline TiVi & tissue viability imager \\
\hline
\end{tabular}




\section{Table of contents}

List of original papers $\quad \mathbf{v}$

Abbreviations vii

1 Background 1

1.1 The skin 1

1.2 Endothelial dysfunction and insulin resistance 3

1.3 Experimental models for studying microvascular function 4

1.4 Methods for provoking microvascular and metabolic responses 4

1.4.1 Physiological provocations 5

$\begin{array}{ll}\text { 1.4.2 Pharmacological provocations } & 6\end{array}$

1.5 Measurement of microvascular responses in the skin 9

1.5.1 Laser Doppler Flowmetry 9

$\begin{array}{lr}\text { 1.5.2 Laser Speckle Contrast Imaging } & 10\end{array}$

$\begin{array}{ll}1.5 .3 \text { Tissue Viability Imaging } & 10\end{array}$

$\begin{array}{ll}1.5 .4 \text { Other techniques } & 11\end{array}$

1.6 Measurement of metabolic responses in the skin 11

1.6.1 Microdialysis 12

$\begin{array}{ll}\text { 1.6.2 Suction blister } & 12\end{array}$

$\begin{array}{ll}1.6 .3 \text { Lymph sampling } & 13\end{array}$

1.7 Aims of the thesis 14

2 Methods $\quad \mathbf{1 5}$

2.1 Subjects 15

2.2 Provocations 16

$\begin{array}{ll}2.3 \text { Optical measurements } & 17\end{array}$

2.4 Control measurements 19

$\begin{array}{ll}2.5 \text { Biochemical analysis } & 19\end{array}$

2.5.1 Blood samples 19

$\begin{array}{ll}\text { 2.5.2 Microdialysate } & 19\end{array}$

2.6 Data Analysis 20

2.6.1 Reproducibility 20

2.6.2 Dose-response model 20

$\begin{array}{ll}\text { 2.6.3 Perfusion half-life } & 21\end{array}$

3 Review of the studies

3.1 Comparison of techniques for measuring microvascular responses 22

3.1.1 Experimental design $\quad 22$

3.1.2 Results 23

3.2 The dynamics of microvascular responses to pharmacological provocations in the skin

3.2.1 Experimental design $\quad 25$

3.2.2 Results 25

3.3 The microvascular response to insulin in the skin 27

$\begin{array}{ll}\text { 3.3.1 Experimental design } & 27\end{array}$

3.3.2 Results 28

3.4 Microvascular and metabolic effects of insulin in the skin 29

3.4.1 Experimental design 29 
3.4.2 Results

4 Discussion $\quad 32$

4.1 Measurement of skin microcirculation $\quad 32$

4.2 Analysing dynamics of skin perfusion 33

4.3 Microvascular and metabolic actions of insulin in the skin 34

4.4 Limitations 36

5 Conclusion $\quad 38$

6 Future perspectives

$\begin{array}{ll}\text { Acknowledgements } & \mathbf{4 0}\end{array}$

References $\quad 42$ 


\section{Background}

This thesis is about the investigation of microvascular and metabolic responses in the skin during local and systemic provocations. The microcirculation is of key importance in the regulation of tissue perfusion and ensures adequate delivery of nutrients, oxygen, and hormones, as well as the removal of waste products. It is comprised of a network of small vessels, including arterioles, venules and capillaries, which function as an exchange surface between the plasma compartment and the tissue interstitium.

Among the conventional cardiovascular risk factors including; obesity, insulin resistance and hypertension, microvascular dysfunction is common (Davignon et al, 2004; Levy et al, 2008; Meigs et al, 2006; Tziomalos et al, 2010). Insulin itself has vasodilatory actions that augment the delivery of glucose to muscle cells, and this capacity seems to be impaired in states of insulin resistance and hypertension (Baron, 1994; Clark et al, 2003). Experimental techniques for investigating the interactions between human microcirculation and tissue metabolism are of great interest, particularly as changes in microvascular function can already occur before the clinical manifestation of cardiovascular events (Antonios et al, 1999; Meigs et al, 2004; Meigs et al, 2006). Improved experimental techniques help to better understand the physiology and pathophysiology of the microcirculation, which in turn could lead to better therapeutic strategies in cardiovascular and metabolic disease states.

Existing models that have been used for this purpose have often focused on muscle, which is considered one of the main target organs of insulin. In recent years, however, the skin has become a popular surrogate organ for studying microvascular responses, including those related to the actions of insulin. However, many methodological aspects of studying these responses, including the choice of provocations and measurement techniques, have not been elucidated. Therefore, in this thesis, the microvascular and metabolic responses to provocations in the human skin are studied in vivo using minimally-invasive measurement techniques. Also, methodological aspects of these measurement techniques are studied.

\subsection{The skin}

The skin is one of the largest organs of the body and has many functions. It forms a mechanical barrier between the underlying tissue and the external environment. The skin also serves as an immunologically active organ, is richly innervated with nerves of the sensory system, protects underlying tissue from UV radiation, helps regulate body temperature, forms a surface for grip, plays a role in vitamin $\mathrm{D}$ production, and has a cosmetic association. The significance of the skin becomes clear when damages to the 
tissue, such as a burn or a wound occur, resulting in loss of body fluids and creating opportunity for bacteria to invade (Gawkrodger, 2012).

The skin is composed of three layers. The most external layer, the epidermis, is a stratified squamous epithelium and is about $0.1 \mathrm{~mm}$ thick, but the thickness can be up to $1.6 \mathrm{~mm}$ on palms and soles. The middle layer, the dermis, consists of a supportive connective layer of collagen that supplies strength and has elastin fibres for elasticity. The inner, subcutaneous layer, consist of adipose and loose connective tissue. The skin has a rich and dynamic blood supply that forms the cutaneous microcirculation (Gawkrodger, 2012). There is no universally accepted definition of microcirculation, although the term is generally taken to include vessels $<150 \mu \mathrm{m}$ in diameter, including arterioles, capillaries and venules (Levy et al, 2001). In the skin, arteries from the subcutaneous layer branch upwards and form two horizontal plexuses, consisting of arterioles and venules. The lower plexus, formed by perforating vessels from underlying muscle and subcutaneous fat, gives rise to arterioles and venules that connect with the superficial plexus. From the superficial plexus, at the boundary of papillary and reticular dermis, nutritive capillary loops arise. Arteriovenous shunts connect the two plexuses and have an important role in thermoregulation (Braverman, 2000; Walloe, 2016). Nutritive blood flow refers to the route in direct contact with target cells, while nonnutritive refers vascular shunts (Clark et al, 2000). In the skin, capillary perfusion is regulated by terminal arterioles that feed capillary units. Periodic changes in the diameter of the terminal arterioles, vasomotion, have been proposed to be one explanation to the regulation of which of the capillary units to get perfused (Rossi et al, 2008).

The match between the local metabolic demand and the microvascular perfusion is thus regulated by the arteriolar diameter. Endothelial cells, forming the inner layer of the vessel, are in contact with blood flow and react to vasoactive substances through signal transduction cascades. The endothelium can cause relaxation of the vessels by the release of a variety of relaxing factors, including nitric oxide (NO) and endothelium derived hyperpolarising factors (EDHF). Contracting factors are also produced by the endothelium, including vasoconstriction prostanoids and endothelin-1 (ET-1) (Vanhoutte \& Tang, 2008). The endothelium has a key role in the inhibition of platelets aggregation, the modulation of leukocyte adhesion and transmigration in inflammation, as well as vascular wall permeability. Despite these abilities, the term "endothelial function" is in most cases referred to as the ability of the endothelium to respond to stimuli by release of relaxing factors followed by smooth muscle relaxation (Cracowski et al, 2006). 


\subsection{Endothelial dysfunction and insulin resistance}

Endothelial dysfunction as a result of an impairment of endothelial vascular signalling is one of the earliest vascular changes in the pathogenesis of cardiovascular disease (Holowatz et al, 2008), which is one of the leading causes of death in the world. The term "endothelial dysfunction" refers to a systemic disease process. It is characterised by a reduced ability of the vascular endothelium to properly maintain vascular homeostasis, through attenuated endothelial-dependent vasodilation, augmented vasoconstriction and structural remodelling of the microvessels.

Endothelial dysfunction is common among patients with conventional cardiovascular risk factors, including obesity and insulin resistance. Insulin resistance is typically defined as decreased sensitivity and/or responsiveness to the metabolic actions of insulin that promote glucose disposal. A major action of insulin involves translocation of the insulin-responsive glucose transporter (GLUT-4) to the plasma membrane and activation of downstream pathways of glucose metabolism. However, for insulin to be able to interact with the receptor on the plasma membrane, sufficient insulin and glucose must be delivered to the cells of the tissue first (Serne et al, 2007).

In the past decades, it has become increasingly evident that insulin has important vascular actions, and that the net vascular effect of insulin usually results in vasodilation in healthy individuals. In muscles, insulin has been found to redirect blood flow from non-nutritive to nutritive microvessels, resulting in a net increase of the overall number of perfused nutritive capillary networks. This "capillary recruitment" increases the nutritive blood flow to muscle tissue and subsequently enhances the availability of insulin and glucose (Kubota et al, 2013). The vascular endothelium has been shown to play an important role in capillary recruitment by the release of NO. It has been shown that capillary recruitment by insulin also may occur in the skin (Hohberg et al, 2008) and that this process is impaired in hypertension, obesity and insulin resistance (de Jongh et al, 2004a; de Jongh et al, 2004b).

The association between insulin resistance and endothelial dysfunction is still unknown. It is, however, generally believed that the ability of insulin to increase the capillary surface area is impaired with insulin resistance. Since insulin also has vasoconstrictive effects via the production of ET-1 (Anfossi et al, 2009), this could be due to an imbalance between vasodilatory and vasoconstrictive actions of insulin. The disruption of the vascular actions of insulin is therefore possibly a key mediating factor in the reduced delivery of glucose to skeletal muscle in insulin resistance. 


\subsection{Experimental models for studying microvascular function}

The golden standard to study vascular function and pharmacology is an in vitro model, known as the isolated vessel preparation (Angus \& Wright, 2000). In this model, the vessel wall is strapped to a gauge and the tension generated when submerged in a bath containing a drug solution is correlated to the vasoactive response. The method allows for the mechanical, electrophysiological and biochemical properties of the vessel to be assessed. This model has led to clarification of the importance of the vascular endothelium (Furchgott \& Zawadzki, 1980). The main limitation of this model is that the vessels are taken out of their physiological environment, which hampers the generalizability of the results. The method is also more suitable for larger vessel, which limits direct studies of the microcirculation.

The use of animal models has provided insight in microvascular function. A common model for animal studies is the hamster cheek pouch, which has a highly vascularised cutaneous microcirculatory bed (Panazzolo et al, 2013). Likewise, the rat cremaster muscle is used (Eringa et al, 2002; Eringa et al, 2007). Genetic rodent models such as the Zucker rat has also been popular in the studies of metabolic diseases (Butcher et al, 2013; Eringa et al, 2007). Besides the ethical aspects of animal models, care must be taken when generalising the results gained in animal models to humans. For example, ACh initiates an endothelium-dependent dilation in human ventricular arterioles, while in the porcine circulation an endothelium-independent constriction is observed (Gutterman et al, 2016; Myers et al, 1991).

Given the limitations of animal models, in vivo models for studying microcirculation directly in humans are of great interest. As with in vitro or animal models, important aspects are that (1) microvessels within a specific tissue must be stimulated in a controlled way using specific provocations, (2) the microvascular responses to these provocations must be measured and (3) the measurement data should be adequately analysed and interpreted in order to properly understand the mechanism involved.

\subsection{Methods for provoking microvascular and metabolic responses}

Since basal blood flow or metabolism provides little information about physiological processes and mechanisms, specific provocations need to be done. In the skin, a number of provocations can be applied, depending on the mechanism to be studied. These provocations can be divided into physiological and pharmacological provocations. 


\subsubsection{Physiological provocations}

\subsubsection{Local heating}

Applying heat locally to the tissue is a common method to study microvascular function in the skin. The response of the skin microcirculation to local heating can be described as a biphasic reaction, depending on how fast the heat is applied. Initially an activation of the cutaneous sensory nerves is seen, also known as the axon reflex, by an increase in perfusion during the first 10 minutes, followed by a decrease in perfusion. Secondarily, nitric oxide is released generating a smooth muscle vascular relaxation and increase of the local microvascular blood flow, which is dependent on endothelial function. A plateau of the response is reached after 20-30 minutes (Kellogg, 2006; Minson, 2010; Minson et al, 2001). An attenuated response to local heating has been reported in patients with type 2 diabetes (Fredriksson et al, 2010; Vinik et al, 2001).

\subsubsection{Local cooling}

Local cooling is a provocation where the skin temperature is decreased and maintained at low level, for example at $24^{\circ} \mathrm{C}$ for 40 minutes. Compared to local heating, this provocation has received less attention. The response is characterised by an initial decrease in skin blood flow, followed by a short-term transient increase. After the transient vasodilation a progressive sustained vasoconstriction is observed (Minson, 2010). The mechanism is complex but appears to be mediated by an adrenergic response (Thompson-Torgerson et al, 2007) in combination with decreased nitric oxide synthase (NOS) activity (Hodges et al, 2006).

\subsubsection{Arterial occlusion}

Total arterial occlusion stops the blood flow and thus the movement of red blood cells (RBC) in the microvascular bed. This makes it possible to measure the "biological zero" value for flow-measuring techniques such as laser Doppler flowmetry (LDF) and laser speckle contrast imaging (LSCI). The occlusion can be done with or without prior exsanguination. Exsanguination of the forearm is most commonly performed by first raising the arm, then applying an Esmarch bandage around the arm, and finally occluding the circulation of the upper arm by inflating a pressure cuff. Exsanguination effectively reduces the concentration of blood cells in the tissue, and can therefore be used as a control method to validate measurement techniques that are dependent on RBC concentration (Bergkvist et al, 2015).

\subsubsection{Post-occlusive reactive hyperaemia}

When arterial occlusion is ended, a physiological increase in perfusion, known as post-occlusive reactive hyperaemia (PORH), is observed. The exact mechanism is not fully understood but is believed to be caused by the recirculation of accumulated 
vasodilatory metabolites and local mediators generating a smooth muscle relaxation (Belzowzki et al, 2012). Sensory nerves seem also to be involved in the mechanism, while prostaglandins do not appear to play a vasodilatory role (Lorenzo \& Minson, 2007). Nor does inhibition of the NOS seem to have an impact on the relaxation (Wong et al, 2003). The hyperaemia measured is proportional with the ischemic period (Farnebo et al, 2010b; Tee et al, 2004). In obese patients PORH was used as an indicator for microvascular function and a significant improvement in response was observed 1 year after gastric bypass surgery (Rossi et al, 2011).

\subsubsection{Pharmacological provocations}

\subsubsection{Local provocations}

\subsection{Iontophoresis of vasoactive drugs}

Transdermal iontophoresis is a technique for controlled, non-invasive delivery of drugs to the skin in vivo. The basic principle was introduced during the mid-18th century for delivery of metal ions but has evolved during the 21th century for delivery of peptides and proteins as well (Helmstadter, 2001). Based on the application of a small electric current, drug molecules, contained in an electrode chamber on the skin, are transported at an enhanced rate compared to passive diffusion by use of electrorepulsive forces (Tesselaar \& Sjoberg, 2011; Turner et al, 2008). It has been suggested that the molecules are transported mainly through sweat ducts and hair follicles (Cullander, 1992). There are several factors affecting the efficiency of iontophoretic drug delivery. Such factors are the composition of the formulation $(\mathrm{pH}$, presence of other ions, vehicle/buffers), physicochemical properties of the drug (molecular size, charge, polarity) (Turner \& Guy, 1997) and the experimental protocol (current profile, duration of treatment) (Tesselaar \& Sjöberg, 2011).

A confounding factor in iontophoresis experiments is the non-specific vasodilation, observed during iontophoresis of drugs without vasoactive properties such as sodium chloride or deionised water (Droog \& Sjoberg, 2003; Grossmann et al, 1995). This effect must be considered in the design of iontophoretic protocols. Another important aspect with iontophoresis is that the absolute dose administered is unknown. This is because one a part of the current is carried by counterions that travel from the skin towards the iontophoresis electrode. Another part of the current is carried by other ions in the drug solution than the specific molecule to be delivered to the skin. Both these counterions and co-ions reduce the dose of the drug delivered to the skin.

\subsection{Microdialysis}

Microdialysis is a well-established semi-invasive technique that can be used for local drug delivery to the tissue of interest. It is described in detail under section 1.6.1. 
The technique is based on the principle of diffusion of molecules between a catheter with a semi-permeable membrane and the surrounding tissue.

\subsubsection{Pharmacological agents}

Both iontophoresis and microdialysis have been used to deliver a variety of pharmacological agents for the study of microvascular and metabolic responses in the skin.

Acetylcholine $(\mathrm{ACh})$ is a muscarinic receptor agonist which, since the study by Furchgott and Zawadzki, is considered to be endothelial dependent (Furchgott \& Zawadzki, 1980). The mechanism of action in the skin is not exactly elucidated, but release of NO has been found to be involved (Turner et al, 2008). Some authors have argued for the involvement of prostaglandins (Khan et al, 1997; Noon et al, 1998), while others have shown contrary results (Berghoff et al, 2002; Morris \& Shore, 1996). Also, local sensory nerves have been found to contribute to the response during iontophoresis (Berghoff et al, 2002). Despite the possible involvement of endothelium independent mechanisms, iontophoresis of ACh has, in combination with blood flow measurement, become a common technique for studying endothelial function.

Sodium nitroprusside (SNP) is a NO donor and used as an endothelium independent control in experiments studying endothelial function. The exact mechanism of action is unknown. Membrane bound enzymes have been suggested to be involved in the generation of NO from SNP, leading to both an arterial and venous smooth muscle relaxation (Feelisch, 1998).

Regular insulin (Humulin, Actrapid) is a recombinant form of insulin that is chemically, physically, biologically and immunologically equivalent to human pancreatic insulin. Different insulin analogues, with various properties regarding time of action, have been studied with respect to their microvascular and metabolic effects in tissue. One such example is insulin aspart (Novorapid), which is a rapid-acting monomeric insulin analogue. Insulin aspart has in comparison to regular insulin been found to cause a more rapid and stronger glucose lowering effect in healthy subjects (Mudaliar et al, 1999; Østerberg et al, 2003). The vasoactive properties of insulin are mediated by NO and ET-1 which are released from the endothelium. Insulin acts on insulin receptors on the endothelium, leading to an intracellular signal cascade by different pathways. The PI3K pathway mediates the release of NO, while the mitogenactivated protein kinase pathway leads to the release of ET-1 (Muniyappa et al, 2008). The released NO leads to vasodilation, while ET-1 triggers vasoconstriction (Eringa et al, 2002; Kim et al, 2006; Vincent et al, 2004). Insulin has a plasma half-life of 4-6 minutes and the degradation of insulin mainly takes place in the liver and kidneys (Duckworth et al, 1998). Insulin has previously been delivered locally to adipose tissue (Lindpointner et al, 2010) and muscle (Rosdahl et al, 2000) by microdialysis. Insulin 
has also been delivered to the skin by iontophoresis (Montero et al, 2014; Rossi et al, 2005a; Rossi et al, 2005b; Serne et al, 2002).

Noradrenaline (NA) is a catecholamine that acts both as hormone and neurotransmitter. It has previously been delivered to the skin both by microdialysis (Folkesson et al, 2012) and by iontophoresis (Maley et al, 2015) in studies in which its vasoconstrictive properties where to be investigated.

The L-arginine derivatives NG-nitro-L-arginine methyl ester (L-NAME) and NG-nitro-L-arginine (L-NOARG) have been widely used to inhibit endothelial NOS. L-NAME has been suggested to be a prodrug lacking the effect of NOS inhibition, until it is hydrolysed to L-NOARG (Pfeiffer et al, 1996). L-NAME has been administered to the skin by both using microdialysis (Kimura et al, 2013) and by iontophoresis and has been shown to be a reproducible substance for studying the NO-pathway (Dreyfuss et al, 2013).

Eutectic Mixture of Local Anaesthetics (EMLA) is a mixture of lidocaine and prilocaine, two substances inhibiting the transmission of nerve signals, indicated for dermal anaesthesia. EMLA is commonly applied to the skin prior to iontophoresis of vasoactive drugs to suppress non-specific vasodilation induced by the iontophoretic current (Horiuchi et al, 2004). Application of EMLA has also been used prior the insertion of microdialysis catheters to reduce pain, but is known to have vascular effects which may confound the microvascular response to be investigated (Cracowski et al, 2007).

\subsubsection{Systemic provocations}

While local provocations in the skin have the advantage of preventing systemic effects, systemic provocations have been widely used to study metabolic responses that often affect multiple tissues and organ systems simultaneously.

\subsection{Euglycemic hyperinsulinemic clamp}

The traditional in vivo model to study insulin resistance is the euglycemic hyperinsulinemic clamp. During a constant intravenous infusion of insulin, the plasma glucose level is clamped at about $5 \mathrm{mmol} / \mathrm{l}$ by an intravenous infusion of glucose. When a steady state is reached the delivered amount of glucose equals the amount consumed by the entire body (Ferrannini \& Mari, 1998). While this model enables direct measurement of the effects of insulin on glucose utilisation under steady-state conditions, it is a relatively laborious method in which the whole body is exposed to supraphysiological levels of insulin and glucose. The method also demands continuous experienced supervision of the test subject. 


\subsection{Oral glucose load}

A transient increase in systemic glucose and endogenous insulin concentrations can be induced by an oral glucose load. This provocation is also used as a diagnostic test known as the oral glucose tolerance test (OGTT). With OGTT, a standard glucose load (75 gram) is ingested after an overnight fast. The plasma glucose concentration is then measured 2 hours after glucose ingestion. Depending on the concentration after two hours, and indirectly how rapid glucose is cleared from the blood, the test is used to diagnose and study diabetes, insulin resistance and beta cell function (WHO, 2006). The test can be seen as a systemic provocation that affects the whole body, including peripheral tissues such as the skin.

\subsection{Mixed meal}

The principle of the mixed meal provocation is similar to OGTT, but a standardised drink containing carbohydrates, proteins and fat is given instead. The mixed meal is more physiological and has been used in studies of meal-related microvascular effects (Jonk et al, 2011).

\subsection{Measurement of microvascular responses in the skin}

When the microcirculation or metabolism in the skin is stimulated by a local or systemic provocation, measurements have to be carried out to quantify the microvascular or metabolic responses to the provocation. Many of the techniques that have been developed for measurement of microvascular responses in the skin are optical techniques based on the interaction of light with red blood cells (RBC) in the cutaneous microcirculation. While all these techniques have their strengths and weaknesses, they share the advantage of being completely non-invasive. On the other hand, a limitation of optical techniques is that they cannot measure the absolute perfusion value of the cutaneous blood flow in $\mathrm{ml} / \mathrm{min}$ in relation to a tissue volume (Cracowski et al, 2006). In this work, three different optical techniques (Table 1.1) have been used: laser Doppler flowmetry, Laser Speckle Contrast Imaging and Tissue Viability Imaging.

\subsubsection{Laser Doppler Flowmetry}

Laser Doppler flowmetry (LDF) can be considered one of the standard methods for cutaneous blood flow measurement. With LDF, low-power laser light impinges on the tissue and the individual photons migrate through the tissue in a random fashion. Interaction with moving objects, such as blood cells, shifts the scattered photons in frequency, a phenomenon known as the Doppler effect. A photodetector measures the frequency-shifted and frequency-unshifted photon mix. The local intensity variation is mainly determined by the tissue perfusion. The perfusion is defined as the number of RBC multiplied by their mean velocity (Bonner \& Nossal, 1981). 


\subsubsection{Laser Speckle Contrast Imaging}

Laser Speckle Contrast Imaging (LSCI) is a camera-based imaging technique for blood flow measurement (Briers et al, 2013). It is based on the analysis of reflected light from a divergent laser beam that illuminates the tissue. This reflected light forms a speckle pattern on the camera sensor, the dynamics of which depend on the movement of RBC in the tissue. LSCI is able to scan a larger area of skin (typically $15 \times 15 \mathrm{~cm}$ ) in a time frame of a few seconds while at the same time maintaining a high spatial resolution $(0.2 \mathrm{~mm} / \mathrm{pixel}$ at $25 \mathrm{~cm}$ distance). The technique has been shown to have a better reproducibility than LDF (Puissant et al, 2013; Roustit et al, 2010), and this has been attributed to the fact that blood flow changes can be assessed in an area instead of in a single point.

\subsubsection{Tissue Viability Imaging}

Tissue Viability Imaging (TiVi) is another technique for assessment of skin microcirculation. The system is based on a digital camera, and uses linearly polarised white light to illuminate the upper layer of the skin, where the light is partly reflected and partly absorbed and scattered within the deep dermal layer. Before reaching the detector in the camera, the reflected light is filtered by a perpendicularly placed polariser. Therefore, the detected image primarily contains information from subepidermal layers. The RBC in the microcirculation are prone to absorb light in the green wavelength region (about 500-600 nm), to a higher extent than in the red wavelength region (about 600-700 nm), while the surrounding tissue absorb green and red light to approximately the same amount. The concentration of RBC in the skin is estimated by analysing the pixel values in the different colour planes of the image acquired by the camera, using an algorithm that is based on the characteristic absorption spectrum of haemoglobin in the skin (O'Doherty et al, 2007). TiVi has been found more sensitive than LDF in the assessment of vasoconstrictor responses in the skin (Petersen et al, 2010).

\begin{tabular}{|c|c|c|c|}
\hline & LDF & LSCI & TiVi \\
\hline Measurement principle & Doppler effect & Speckle contrast & $\begin{array}{l}\text { Polarisation } \\
\text { spectroscopy }\end{array}$ \\
\hline $\begin{array}{l}\text { Measurement } \\
\text { parameter }\end{array}$ & $\begin{array}{l}\text { Perfusion }(\mathrm{RBC} \\
\text { concentration } \times \\
\text { average RBC } \\
\text { velocity) }\end{array}$ & $\begin{array}{l}\text { Perfusion }(\mathrm{RBC} \\
\text { concentration } \times \\
\text { average } \mathrm{RBC} \text { velocity) }\end{array}$ & $\mathrm{RBC}$ concentration \\
\hline Spatial resolution & $*$ & $500 \mu \mathrm{m}$ & $50 \mu \mathrm{m}$ \\
\hline Measurement area & $\sim 1 \mathrm{~mm}^{2}$ & $15 \times 15 \mathrm{~cm}^{2}$ & $40 \times 40 \mathrm{~cm}^{2}$ \\
\hline Temporal resolution & $33 \mathrm{~Hz}$ & Up to $44 \mathrm{images} / \mathrm{s}$ & Up to 25 images/s \\
\hline Measurement depth & $\sim 0.5 \mathrm{~mm}$ & $\sim 0.2-0.3 \mathrm{~mm}$ & $\sim 0.4-0.5 \mathrm{~mm}$ \\
\hline
\end{tabular}

Table 1.1. Comparison of the main properties of the optical techniques used in the studies. * since LDF measures perfusion in a single-point, the spatial resolution (distance between adjacent measurement points) is not defined. 


\subsubsection{Other techniques}

Besides the techniques used in this work, a number of other techniques have been of importance for measuring microvascular responses in the skin. As of today, most of them are based around optical measurement, but clearance techniques have also been used.

\subsubsection{Capillary microscopy}

Intravital capillary microscopy is a method for direct visualisation of perfused capillaries in the skin. Commonly a field of about $1 \mathrm{~mm}^{2}$ on the dorsal nail fold of a finger is studied using an optical microscope. Perfused capillaries are counted before and after a provocation, such as arterial occlusion with a finger cuff (Clark, 2008). Only the capillaries filled with RBC will be visualised, with the risk of the true number of capillaries being underestimated.

\subsubsection{Clearance techniques}

Skin microvascular blood flow can be assessed using the clearance of different molecules. Ethanol clearance (Hickner et al, 1991) and urea clearance (Farnebo et al, 2011) have been used within microdialysis studies (described under 1.6.1) and are based on the principle that a marker, with a known concentration, added to the perfusate, diffuses through the semipermeable membrane of the microdialysis catheter into the interstitium, and this diffusion is partly dependent on the local blood flow. An estimate of the blood flow is then obtained by measuring the concentration of the marker in the dialysate, which is inversely proportional to local blood flow (Farnebo et al, 2010a).

Similarly, the clearance of radioisotopes can be used for blood flow assessment. In radioisotope clearance studies, gamma radiation is measured over time, after the administration of the isotope, and the wash out is correlated to blood flow. One method is based on Xenon-133 $\left({ }^{133} \mathrm{Xe}\right.$ ) (Lassen et al, 1964) and has previously been used in the skin (Daly \& Henry, 1980). ${ }^{133} \mathrm{Xe}$ clearance has been found equivalent to the microdialysis ethanol clearance technique for measurement of blood flow (Hickner et al, 1994). Another method that has been used in the skin based on the same principle is the Technetium-99m clearance technique (Waterhouse et al, 1986).

\subsection{Measurement of metabolic responses in the skin}

Several techniques have been used to study changes in the concentration of endogenous substances or drugs in the interstitium of the skin. Even though the skin is readily accessible, the determination of exact tissue concentrations has been challenging, due to the complexity of the skin as a compartment. 


\subsubsection{Microdialysis}

Microdialysis is a semi-invasive method that makes it possible to monitor the local concentration of molecules in the tissue interstitium and at the same site locally deliver drugs. The principle of the technique is to mimic the passive diffusion effects of capillary blood vessels. It was first adapted by Bito et al. (Bito et al, 1966) and Delgado et al. (Delgado et al, 1972), but later refined by Ungerstedt and Pycock for monitoring neurochemicals in vivo animal experiments (Ungerstedt \& Pycock, 1974). Today the system consists of a small catheter with a semi-permeable membrane that is inserted in a tissue and through which a solution, the perfusate, is pumped. Due to the membrane being semi-permeable, substances in the perfusate can, depending on their molecular size, diffuse out of the catheter into the tissue. Similarly, endogenous substances can diffuse from the tissue into the catheter and be collected as dialysate into microvials. Microdialysis has been used in humans to monitor substances such as inflammatory markers (Mellergard et al, 2008; Sjögren \& Anderson, 2009), energy metabolites (Rosdahl et al, 1998; 2000), hormones (Desvigne et al, 2005; Sandqvist et al, 2011) and to study the local effects of vasoactive drugs on tissue blood flow (Farnebo et al, 2011).

The degree of equilibration between the concentration of a substance in the dialysate and the medium in which it is measured is defined as the relative recovery, while the absolute recovery is defined as the mass of a substance recovered during a defined time period. Recovery is mainly dependent on the perfusion flow rate, the properties and the area of the catheter membrane and the diffusivity of the specific substance in the tissue (Heinemann, 2003; Ungerstedt, 1991). The diffusivity of substances is in turn dependent on its charge and molecular weight (Clough et al, 2002). Other factors are composition of the perfusate and local characteristics such as tissue temperature (Benveniste, 1989).

An advantage of microdialysis is the possibility to study molecular concentrations human tissue in vivo, compared to blood samples that primarily reflect systemic concentrations. A disadvantage is the trauma generated during the insertion of the catheter (Sjögren \& Anderson, 2009).

\subsubsection{Suction blister}

In the suction blister model a constant negative pressure is applied to a skin area, which results in the separation of the epidermis from the dermis. The blister cavity becomes filled with tissue fluid that is sampled and analysed. Benfeldt et al. (Benfeldt et al, 1999) found in a comparative study with microdialysis the technique to be potentially useful in pharmacokinetic studies in skin, although hampered by the tolerability of the sampling procedure, the temporal resolution and reproducibility. Suction blister has previously been used to study variations in glucose levels in interstitial fluid in diabetic patients (Thennadil et al, 2001). 


\subsubsection{Lymph sampling}

Lymph sampling is a technique based on an access to the lymph system and has previously been used in a study of the transendothelial insulin transport in dogs (Yang et al, 1994). Due to invasive basis of the technique and the need of knowledge of the lymph drainage of a specific skin site, the technique is not optimal for studies in human skin. 


\subsection{Aims of the thesis}

\section{General}

The aim of this project was to develop experimental in vivo models that allow for minimally invasive investigations of responses in the skin to systemic and local microvascular and metabolic provocations. In particular, the project aimed to study the effects of insulin in the skin.

Specifically, the aims of the investigations were:

I - To compare three different optical techniques for measurement of microvascular responses to common pharmacological and physiological provocations in the skin with respect to sensitivity and reproducibility.

II - $\quad$ To study how the drug delivery protocol and local drug dynamics affect the microvascular response during iontophoresis of acetylcholine, methacholine and noradrenaline.

III - To investigate whether regular insulin and insulin aspart has vasoactive effects in the skin when given using iontophoresis, and whether these effects are partly or completely mediated by the release of NO.

IV - To study the metabolic and vascular actions of insulin in the skin, when it is endogenously produced and delivered to the skin via the systemic circulation or directly delivered to the interstitium using microdialysis. 


\section{Methods}

\subsection{Subjects}

In all studies healthy volunteers participated after both written and oral information about the study. Informed consent was always obtained. Demographic data of the subjects is found in Table 2.1. Due to the fact that many factors have been proposed to interfere with the measurement results, participants were interviewed and examined before the start of the experiments. The participants were asked regarding cardiovascular diseases and skin diseases. Smokers were excluded due to the risk of impaired microvascular function (IJzerman et al, 2003) and potential endothelial dysfunction (Heitzer et al, 2000). All participants were asked to refrain from drinks containing caffeine due to effect on microvascular function in healthy individuals (Noguchi et al, 2015). Subjects with a blood pressure above 140/90 $\mathrm{mmHg}$ were excluded as microvascular function has been correlated to blood pressure (Serne et al, 1999). All participants were asked to avoid strenuous exercise on the day of the experiment, although effects of training probably persist over longer time (Lanting et al, 2016). The subjects were asked for biometric data regarding length and weight before the start of the study. In study IV, insulin resistance was assessed using the HOMA model (Matthews et al, 1985).

All experiments were done in a temperature-controlled room at Linköping University hospital. Ceiling lights were dimmed and the curtains of the room were closed to avoid interference by of external light with the optical measurement instruments. The subject lay in a semi-supine position. All studies were approved by the regional ethics committee in Linköping, Sweden, and were done according to the declaration of Helsinki.

\begin{tabular}{lllcl}
\hline Study & Experiment & $\begin{array}{c}\text { Male/ } \\
\text { female }\end{array}$ & $\begin{array}{c}\text { Age } \\
\text { (years) }\end{array}$ & $\begin{array}{c}\text { BMI } \\
\left(\mathbf{k g} / \mathbf{m}^{2}\right)\end{array}$ \\
\hline I & 1 & $7 / 3$ & $24.5 \pm 2.5$ & $23.7 \pm 1.5$ \\
& 2 (LDF, LSCI) & $10 / 2$ & $25.2 \pm 2.1$ & $22.8 \pm 2.7$ \\
& 2 (TiVi) & $6 / 4$ & $26.5 \pm 7.5$ & $23.2 \pm 1.9$ \\
& 3 & $7 / 3$ & $24.5 \pm 2.5$ & $23.7 \pm 1.5$ \\
& 1 & $12 / 9$ & $28 \pm 6$ & $23 \pm 3$ \\
II & 2 & $6 / 3$ & $24 \pm 3$ & $*$ \\
& 2 & $7 / 5$ & $28 \pm 4$ & $22 \pm 3$ \\
& 3 & $4 / 7$ & $26.3 \pm 3.3$ & $23.7 \pm 3.6$ \\
III & & $7 / 7$ & $23 \pm 5.1$ & $22.6 \pm 2.1$ \\
IV & & & & \\
\hline
\end{tabular}

Table 2.1 Demographic data of the subjects included in each study. Data presented as mean $\pm S D . *$ indicate that length was not registered, weight $64 \pm 9 \mathrm{~kg}$. 


\subsection{Provocations}

In table 2.2 an overview of the provocations that were given, including the respective mechanism they target is listed. In study I, II and III, constant-current iontophoresis was used to deliver drugs to the skin, using two identical iontophoresis supplies (Prion 382, Perimed AB, Järfälla, Sweden). Drug delivery electrodes (PF 383, Perimed AB, Järfälla, Sweden) were mounted to the blood flow probe when LDF was used (Figure 2.1). For pretreatment in study III and when blood flow was measured with LSCI or TiVi, drugs were delivered by transparent ring-shaped iontophoresis electrodes (LI 611, Perimed AB, Järfälla, Sweden). To complete the electrical circuit dispersive electrodes (PF 384, Perimed AB, Järfälla, Sweden) were mounted on the skin. Drug delivery electrodes were always placed on the volar side of the forearm and care was taken to avoid visible veins and birthmarks.

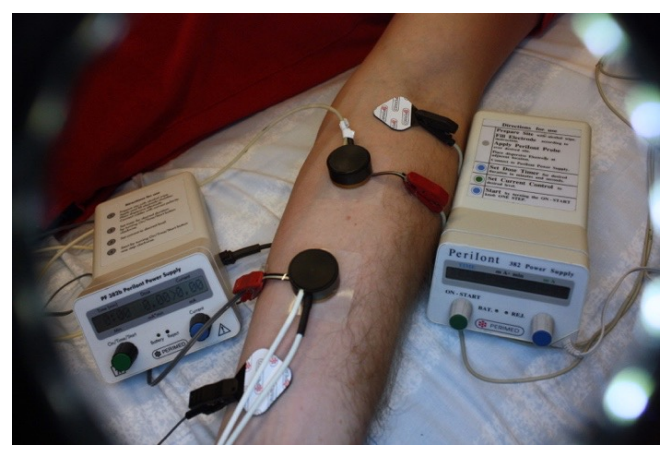

Figure 2.1. Photo of two iontophoresis supply units and drug delivery electrodes. Photo by Fredrik Iredahl.

In study IV, $100 \quad 000$ Dalton microdialysis catheters with a membrane length of $10 \mathrm{~mm}$ (CMA 71, M dialysis $\mathrm{AB}$, Stockholm, Sweden) were inserted at the volar side of the forearm. The insertion was made by an 18-Gauge cannula (BD Venflon Pro, Becton Dickinson Infusion Therapy AB, Helsingborg, Sweden) that was pushed through the skin, after local anaesthesia by $0.1 \mathrm{ml}$ Xylocaine (Xylocain $20 \mathrm{mg} / \mathrm{ml}$, AstraZeneca, Södertälje, Sweden). The steel mandrin from the cannula was then removed and replaced with the microdialysis catheter. When the microdialysis catheter was in place the plastic part of the cannula was removed. The microdialysis catheters were inserted parallel to each other at a $3 \mathrm{~cm}$ distance and each catheter was connected to a microinjection pump (CMA 71, CMA AB, Solna, Sweden). During microdialysis, blood flow measurements were done using LSCI (Figure 2.2).

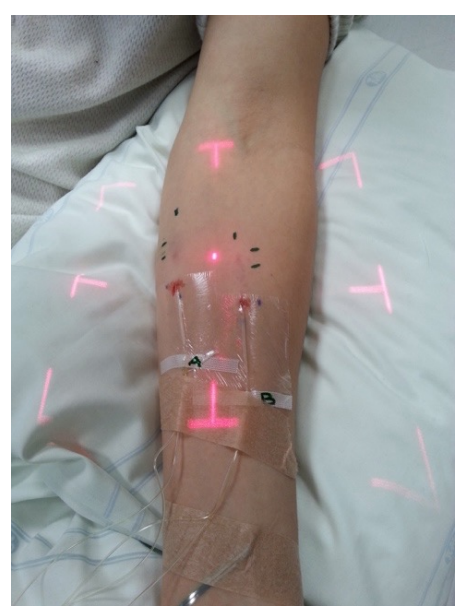

Figure 2.2. Photo of the microdialysis catheters and the red laser crosshair indicating the measuring area for LSCI. Photo by Alexandra Högstedt. 
In study IV local blood flow was also indirectly measured by urea clearance. The relative loss of added urea is proportional to local blood flow (Farnebo et al, 2011). The concentration of urea in the dialysate was analysed with a CMA 600 measurement system (CMA Microdialysis, Stockholm).

\begin{tabular}{|c|c|c|c|}
\hline Study & Provocation & Mechanism & $\begin{array}{l}\text { Measurement } \\
\text { technique }\end{array}$ \\
\hline I & Iontophoresis of SNP & NO donor, smooth muscle relaxation & LDF, LSCI, TiVi \\
\hline $\mathrm{I}+\mathrm{II}$ & Iontophoresis of NA & $\begin{array}{l}\text { Alpha-adrenergic stimulation, smooth } \\
\text { muscle contraction }\end{array}$ & $\begin{array}{l}\text { LDF, LSCI, TiVi } \\
\text { (Study II - TiVi) }\end{array}$ \\
\hline I & Local heating & $\begin{array}{l}\text { Biphasic: (I) activation of cutaneous } \\
\text { sensory nerves (axon reflex); (II) nitric } \\
\text { oxide release, smooth muscle relaxation. }\end{array}$ & LDF, LSCI, TiVi \\
\hline I & $\begin{array}{l}\text { Exsanguination, } \\
\text { occlusion, PORH }\end{array}$ & $\begin{array}{l}\text { (I) Ischemia by exsanguination and total } \\
\text { occlusion; (II) Recirculation of } \\
\text { accumulated vasodilatory metabolites, } \\
\text { smooth muscle relaxation. }\end{array}$ & LDF, LSCI, TiVi \\
\hline II & Iontophoresis of ACh & Muscarinic receptor agonist & $\mathrm{LDF}$ \\
\hline II & Iontophoresis of MCh & Muscarinic receptor agonist & LDF \\
\hline III & Iontophoresis of L-NAME & Inhibition of eNOS & $\mathrm{LDF}$ \\
\hline III & Iontophoresis of insulin & $\begin{array}{l}\text { Binds to insulin receptor, NO and ET-1 } \\
\text { release }\end{array}$ & $\mathrm{LDF}$ \\
\hline IV & Microdialysis of insulin & $\begin{array}{l}\text { Binds to insulin receptor, NO and ET-1 } \\
\text { release }\end{array}$ & $\begin{array}{l}\text { Microdialysis, } \\
\text { LSCI }\end{array}$ \\
\hline IV & Systemic glucose load & $\begin{array}{l}\text { Increases blood glucose, release of } \\
\text { pancreatic and gut peptides. }\end{array}$ & $\begin{array}{l}\text { Microdialysis, } \\
\text { LSCI }\end{array}$ \\
\hline
\end{tabular}

Table 2.2 Overview of the provocations applied in each study, their mechanisms and measurement techniques used.

\subsection{Optical measurements}

A laser Doppler perfusion monitor (Periflux 5000, Perimed AB, Järfälla, Sweden) (Figure 2.3) was used in study I, II and III. For the local heating a thermostatic laser Doppler probe (Probe 457, Perimed AB, Järfälla, Sweden) was used, and for the iontophoresis experiments a thermostatic laser Doppler probe (Probe 481-1, Perimed 
$A B$, Järfälla, Sweden) was used. Both probes have a fibre separation of $0.25 \mathrm{~mm}$ and measure perfusion at depth of approximately $0.5 \mathrm{~mm}$. Perfusion values were measured at a sample rate of 33 recordings per second and were generated by the manufacturer's program (Perisoft 2.5.5, Perimed AB, Järfälla, Sweden).

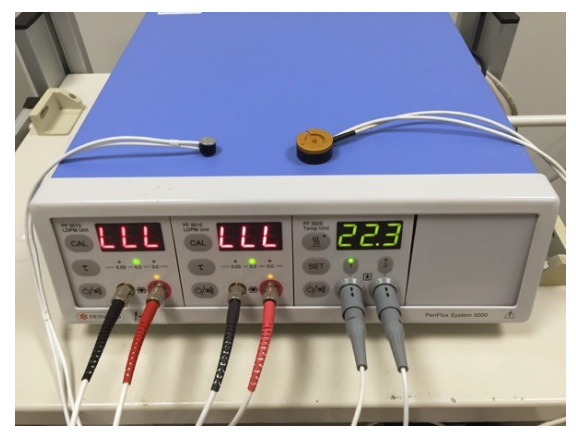

Figure 2.3. The $L D F$ device used in the studies.

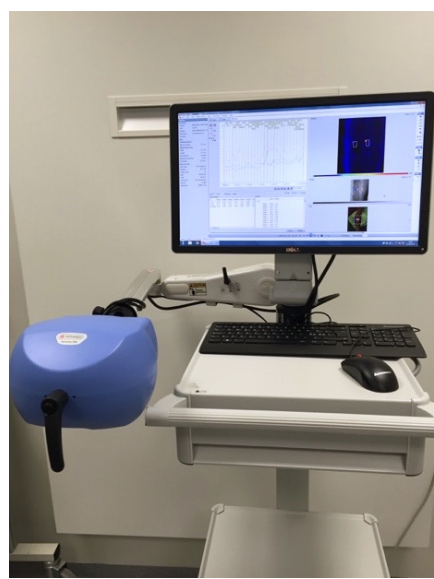

Figur 2.4. The LSCI device used in the studies.

A laser speckle contrast imager (Pericam PSI, Perimed AB, Järfälla, Sweden) (Figure 2.4) was used in study I and IV. The system uses a divergent laser beam with a wavelength of $785 \mathrm{~nm}$ and is assigned to Class 1 laser, which means that there are no limitations to safe use of the instrument. Perfusion images were acquired by averaging data from 42 image frames, taken during 2 seconds. Data were analysed by calculating mean perfusion level within defined regions of interest using the manufacturer's program (PIMsoft 1.3, Perimed AB, Järfälla, Sweden).

A tissue viability imager (TiVi600, Wheelsbridge AB, Linköping, Sweden) was used in study I and II. The system consists of a digital camera (Canon EOS 550D) with perpendicular polarisation filter in front of the lens and flash (Figure 2.5). Images were analysed by calculating the TiVi-index within defined regions of interest using analysis software (TiVi version 2.1, Wheelsbridge AB, Linköping Sweden). In all experiments where simultaneous measurements were made by TiVi and LSCI, care was taken to avoid interference with the

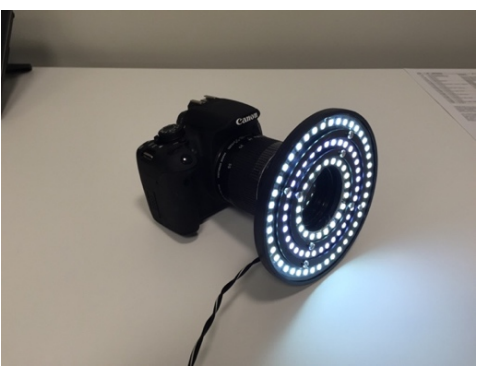

Figure 2.5. The TiVi camera used in the studies. LSCI laser light. 


\subsection{Control measurements}

Control measurements were done to be able to correct for microvascular and metabolic responses that are unrelated to the studied physiological mechanism. In study I-III control measurements were done within the same individual, while a separate control group was included in study IV to control for the effect of microdialysis catheter insertion on microvascular and metabolic responses.

Phosphate buffer saline (PBS) was used as a control solution for L-NAME, monomeric insulin and insulin aspart in study III.

In study IV insulin diluting medium (Insulin Diluting Medium for Novorapid and Levemir, Novo Nordisk A/S, Bagsværd, Denmark) was used as control solution for insulin aspart (Novorapid $100 \mathrm{U} / \mathrm{mL}$, Novo Nordisk A/S, Bagsværd, Denmark). Insulin diluting medium is identical to the insulin aspart drug solution, but does not contain the insulin.

In all experiments involving iontophoresis and microdialysis, the subjects were blinded to which substances were administered at which site.

\subsection{Biochemical analysis}

\subsubsection{Blood samples}

In study IV venous blood samples were collected from the median cubital vein to assess plasma glucose, by a hexokinase enzymatic method, and serum insulin, by electrochemiluminescence. The samples were directly analysed by the clinical laboratory at Linköping University hospital.

Capillary blood glucose was monitored in study IV by alternately puncturing the index, middle and ring finger using a lancet. Capillary blood samples were thereafter analysed by a spectrophotometer (Glucose 201+ system, HemoCue AB, Ängelholm, Sweden).

\subsubsection{Microdialysate}

The concentration of glucose, lactate, pyruvate and urea in the dialysate was analysed by the CMA 600 Microdialysis Analyser (CMA AB, Solna, Sweden). The analysis is based on enzymatic methods. A filter photometer measures the formation of the red-violet substance quinoneimine at $546 \mathrm{~nm}$ generated by glucose, lactate and pyruvate. Urea was analysed based on the rate of utilisation of NADH at $365 \mathrm{~nm}$. 
The insulin concentration was analysed by an enzyme-linked immunosorbent assay (Ultrasensitive ELISA, Mercodia, Uppsala, Sweden). Since the minimum analysis volume of the method is $25 \mu$, dialysate from consecutive microvials were pooled in order to obtain a higher temporal resolution of the other analysed molecules.

\subsection{Data Analysis}

\subsubsection{Reproducibility}

In study I inter-subjective variability was assessed in all experiments, while siteto-site variability of TiVi and LSCI during baseline was assessed in the third experiment. Variability was assessed using the coefficient of variation $(\% \mathrm{CV})$ which is defined as:

$$
\% C V=\frac{S D}{\mu} \times 100 \%
$$

where $\mathrm{SD}$ is the standard deviation and $\mu$ is the mean of the sample. Because $\% \mathrm{CV}$ is independent of the measurement unit, it can be used for comparison between measurement techniques that have measurement values in different units.

\subsubsection{Dose-response model}

The sigmoidal $\mathrm{E}_{\max }$ model was used in study II, experiment 2 to characterise the response to $\mathrm{ACh}$. The model can be described by the following equation:

$$
E(C)=E_{\text {min }}+\frac{\left(E_{\max }-E_{\min }\right) C^{n}}{C^{n}+E D_{50}^{n}}
$$

Where $E$ is the response elicited by the drug, $E_{\min }$ is the minimum response, $E_{\max }$ is the maximum response, $C$ is the drug concentration, $E D_{50}$ is the concentration that is needed to elicit half of the maximum response and $n$ is the Hill slope. The Hill slope defines the steepness or slope factor; a steeper curve has a higher slope factor.

The model has previously been adapted to model blood flow response after iontophoresis (Henricson et al, 2007), the equation then is described as follows:

$$
E(t)=E_{\text {min }}+\frac{\left(E_{\max }-E_{\min }\right) D(t)^{n}}{D(t)^{n}+E D_{50}^{n}}
$$

Where $D$ is the iontophoretic charge applied over the skin, which depends on both current strength and the time applied $D(t)=I x t . E D_{50}$ is the electrical charge needed to elicit half the maximum response. 


\subsubsection{Perfusion half-life}

The recovery phase after iontophoresis of ACh and methacholine (MCh) in study II was modelled using an exponential decay function:

$$
E(t)=E_{0} \exp (-\lambda \mathrm{t})
$$

Where $\mathrm{E}_{0}$ is the response amplitude at the beginning of the recovery phase, $\lambda$ is the clearance rate factor and $t$ is the time. The perfusion half-life was defined in these experiments as the time for the perfusion to decrease to $50 \%$ of its initial maximum value:

$$
T_{1 / 2}=\frac{\ln (2)}{\lambda}
$$

Where $T_{1 / 2}$ is the perfusion half-life, $\ln (2)$ is the natural logarithm of 2 and $\lambda$ is the clearance rate factor. 


\section{Review of the studies}

3.1 Comparison of techniques for measuring microvascular responses

\subsubsection{Experimental design}

The study involved experiments designed to compare the suitability of LSCI and TiVi with LDF for measuring responses to pharmacological and physiological provocations in the skin. Changes in skin microcirculation were measured in healthy subjects during three experiments with different provocations; (1) iontophoresis of NA and SNP, (2) local heating and (3) occlusion, exsanguination and PORH (Figure 3.1).

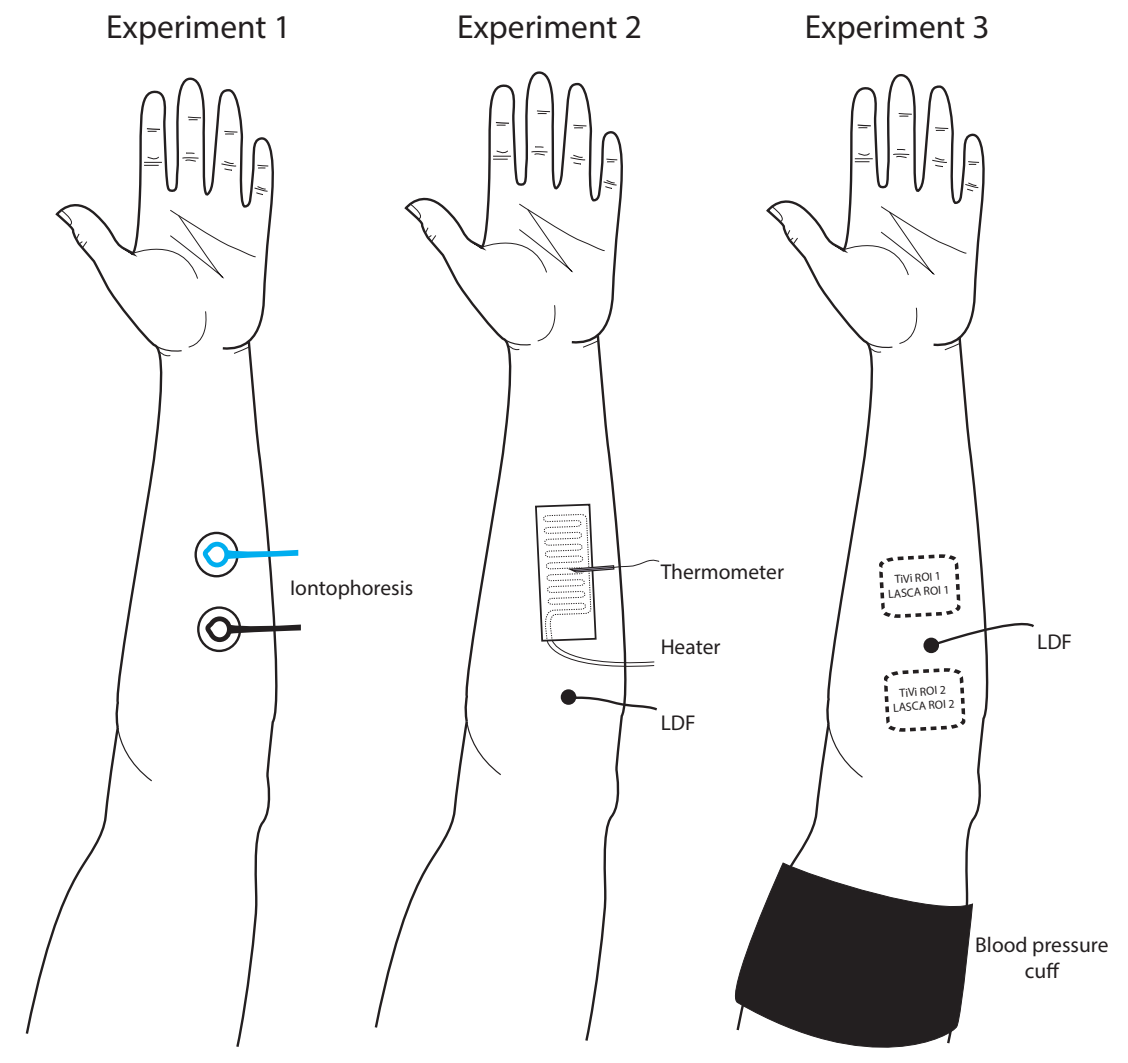

Figure 3.1. Schematic diagram of the experimental setup in study I. The different skin sites used for measurement of microvascular responses to pharmacological and physiological provocations. 


\subsubsection{Results}

During iontophoresis of NA no change in perfusion was observed (LDF: $p=$ 0.64; LSCI: $p=0.64$ ), while a significant decrease in RBC concentration was observed (TiVi: $p=0.02$ ). A significant vasodilation was observed with all techniques after iontophoresis of SNP (Figure 3.2).

LDF

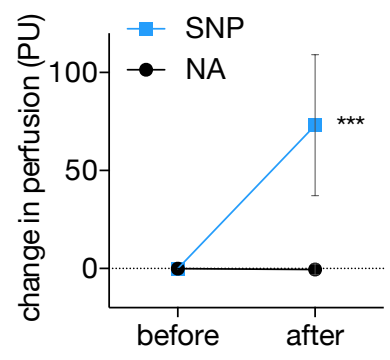

LSCI

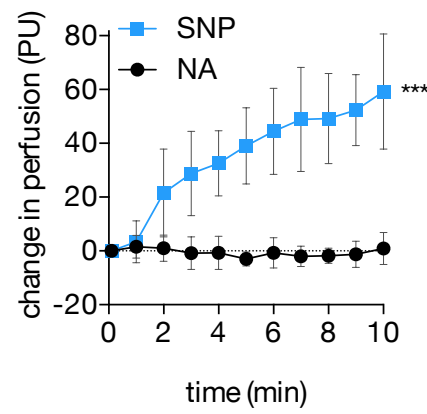

TiVi

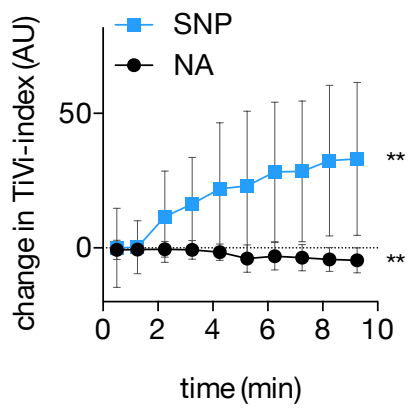

Figure 3.2. Study I, Experiment 1. Skin microvascular response during iontophoresis of sodium nitroprusside (SNP) in blue and noradrenaline (NA) in black as measured using laser Doppler flowmetry (LDF), Laser Speckle Contrast Imaging (LSCI) and Tissue Viability Imaging (TiVi) $(n=10)$. Error bars represent mean $\pm S D$. *** indicates a significant change from baseline $(p<0.001)$, ** indicates $p<0.01$.

Local heating significantly increased skin perfusion (LDF $\mathrm{p}<0.001$; LSCI $\mathrm{p}<0.001)$ and RBC concentration (TiVi $\mathrm{p}<0.001)$ (Figure 3.3).

LDF

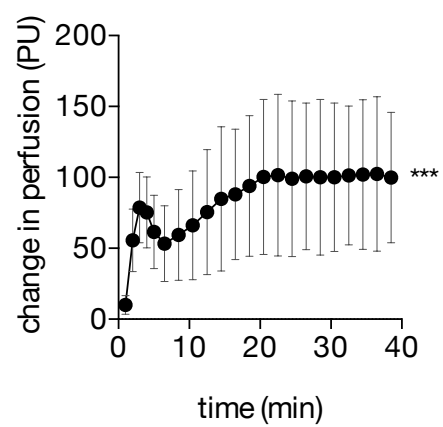

LSCI

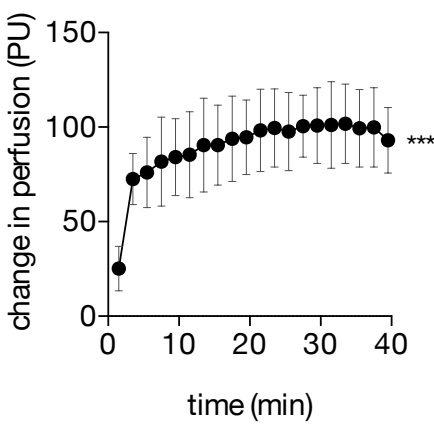

TiVi

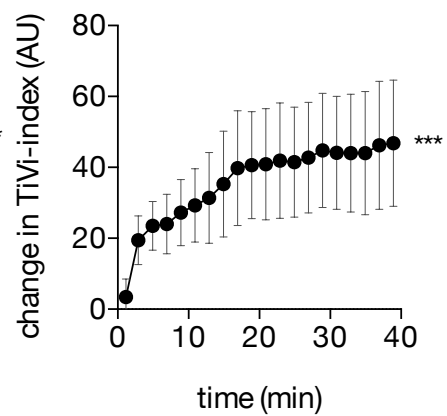

Figure 3.3. Study I, Experiment 2. Skin microvascular responses to 40 minutes of local heating as measured using laser Doppler flowmetry (LDF, $n=12)$, Laser Speckle Contrast Imaging (LSCI, $n=12$ ) and Tissue Viability Imaging (TiVi $n=10)$. Error bars represent mean $\pm S D$. $* * *$ indicates significant change from baseline $(p<0.001)$. 
During exsanguination a significant decrease in perfusion (LDF $\mathrm{p}=0.004$; LSCI $\mathrm{p}<0.001$ ) and RBC concentration (TiVi $\mathrm{p}=0.026$ ) was observed. During arterial occlusion without prior exsanguination, only LSCI observed a significant change in perfusion $(p<0.001)$, while a trend was seen with LDF $(p=0.053)$. No change in RBC concentration, measured by TiVi, was observed after 5 minutes of occlusion without prior exsanguination. The inter-subject variability after 5 min occlusion was $41.4 \%$ (LDF), $30.3 \%$ (LSCI), respectively $24.0 \%$ (TiVi) (Figure 3.4).

LDF

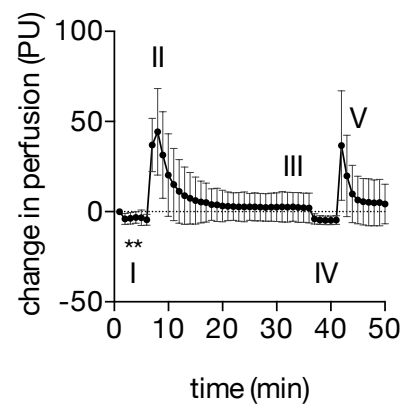

LSCI

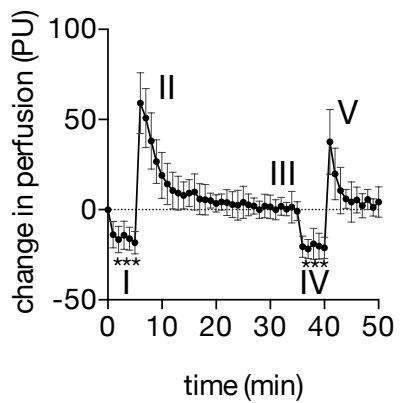

TiVi

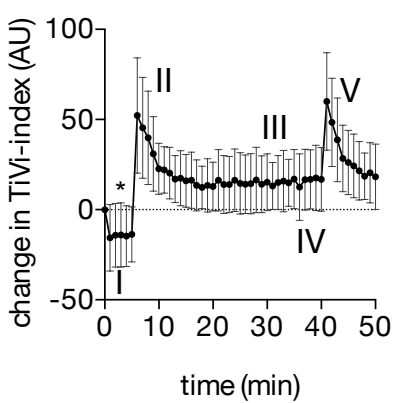

Figure 3.4. Study I, Experiment 3. Skin microvascular responses to (I) occlusion with prior exsanguination, (II) PORH, (III) baseline before occlusion without prior exsanguination, (IV) occlusion without prior exsanguination and (V) PORH. Measured using laser Doppler flowmetry (LDF), Laser Speckle Contrast Imaging (LSCI) and Tissue Viability Imaging (TiVi). $n=10$. Error bars represent mean $\pm S D . *$ indicates significant change from baseline, $p<0.05$. $* *$ indicates $p<0.01 ; * * *$ indicates $p<0.001$. 


\subsection{The dynamics of microvascular responses to pharmacological}

\section{provocations in the skin}

\subsubsection{Experimental design}

Perfusion responses during experiments with iontophoresis may depend on how the drug is delivered and how fast it is removed from the measurement area. We therefore (1) delivered vasoactive drugs with different pharmacokinetic properties (ACh and $\mathrm{MCh}$ ) by iontophoresis and (2) used different drug delivery protocols (a single pulse or five separate pulses of ACh and NA) to study the effect on the perfusion responses as measured using LDF, and RBC concentration as measured by TiVi. In a third experiment (3), ACh was delivered repeatedly by iontophoresis at the same site (Figure 3.5). The perfusion half-life was then estimated as a measure of how fast the perfusion response returns to baseline.

Experiment 1

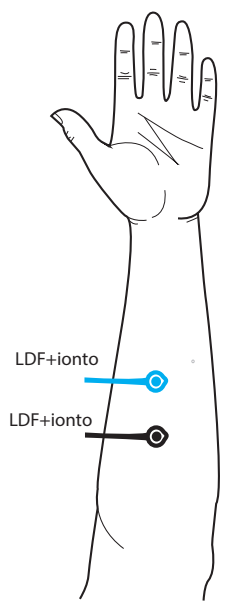

Experiment 2

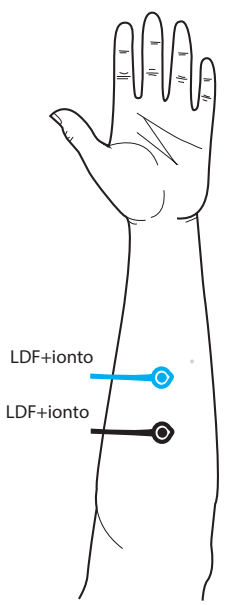

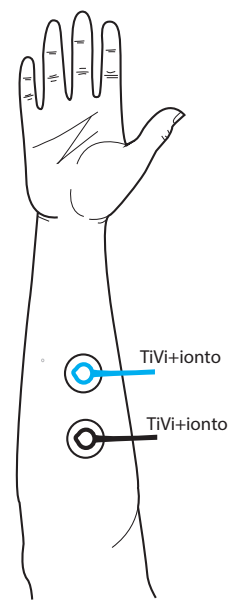

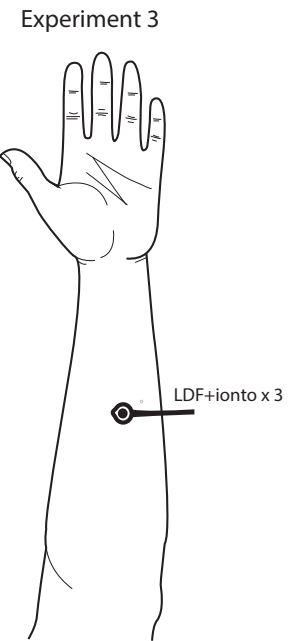

Figure 3.5. Schematic diagram of the experimental setup in study II. The different skin sites used for measurement of microvascular responses to drugs delivered by iontophoresis (ionto). Measurements by laser Doppler flowmetry (LDF) and tissue viability imaging (TiVi).

\subsubsection{Results}

Iontophoresis of $\mathrm{ACh}$ and $\mathrm{MCh}$ generated a similar increase in maximal perfusion $(\mathrm{p}=0.98)$. After iontophoresis of $\mathrm{ACh}$, perfusion decreased rapidly with an estimated perfusion half-life of 6.1 minutes, compared to $\mathrm{MCh}$ with a slow decrease of 41 minutes $(\mathrm{p}<0.001)$. During repetitive iontophoresis of $\mathrm{ACh}$, the perfusion half-life decreased by each repetition $(p<0.001)$. The mean maximum response was lower with the first pulse compared with the subsequent pulses, although the difference was not statistically significant (one-way ANOVA, $\mathrm{p}=0.36$ ). (Figure 3.6). 

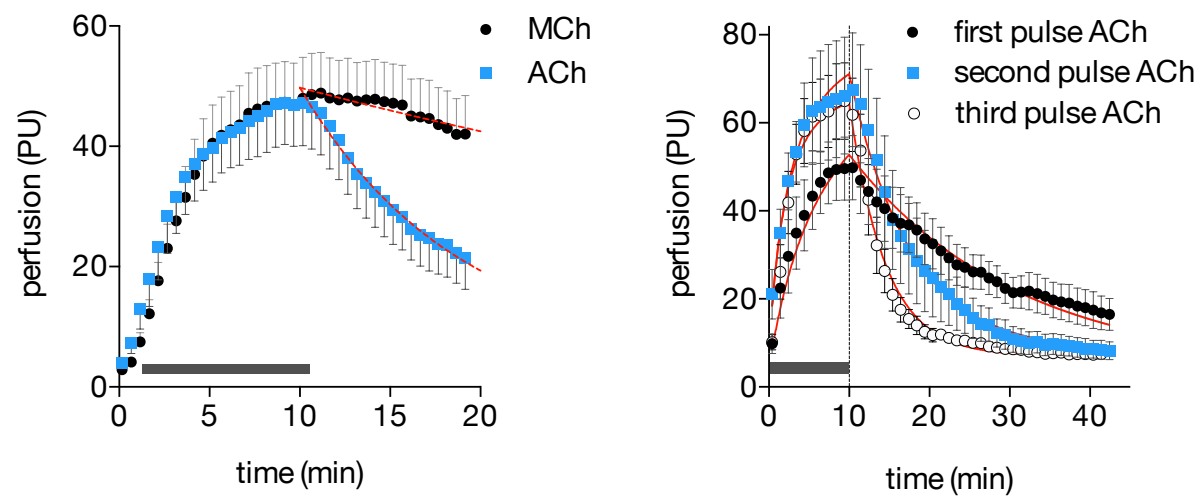

Figure 3.6. Study II, Experiment 1 (left) Experiment 3 (right). Skin microvascular response to methacholine (MCh and, acetylcholine (ACh). Bars indicate the period when the current was given. Red lines indicate curve fits obtained using nonlinear modelling of the responses. Experiment $1 n=21$, experiment $3 n=12$. Error bars represent mean \pm SEM.

When ACh was delivered using a single pulse, a stronger perfusion response was observed compared to when it was delivered using multiple pulses $(\mathrm{p}<0.001)$, while a single pulse protocol of NA resulted in a significantly stronger decrease in $\mathrm{RBC}$ concentration compared to multiple pulses (linear regression, $\mathrm{p}<0.001$ ) (Figure 3.7).

Acetylcholine

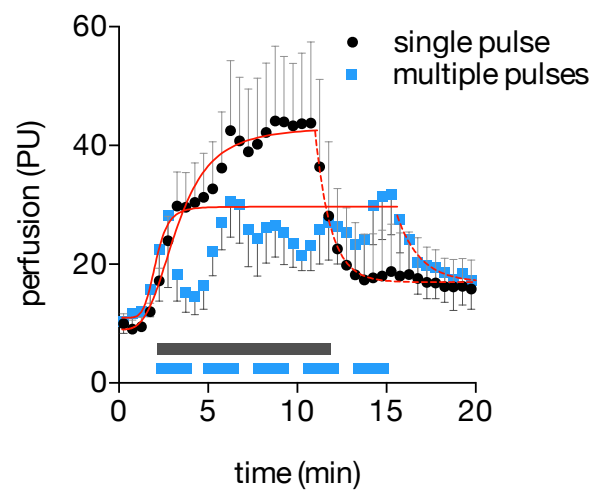

Noradrenaline

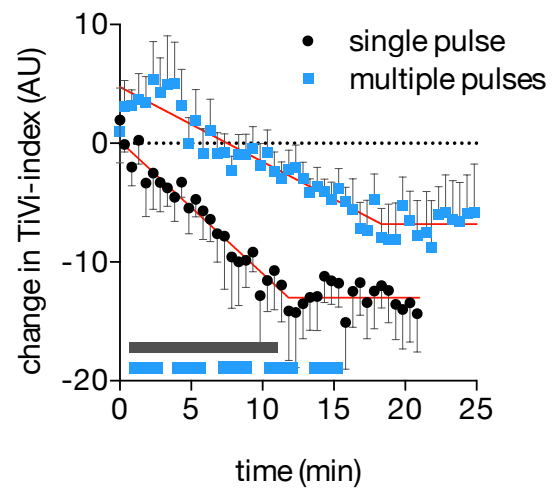

Figure 3.7. Study II, Experiment 2. Microvascular responses to iontophoresis of acetylcholine measured by laser Doppler flowmetry (LDF, left) and noradrenaline measured by tissue viability imaging (TiVi, right). The perfusion response to iontophoresis of acetylcholine using a single current pulse (black) was significantly stronger than with the same dose given using five repeated current pulses (blue) separated by one-minute intervals $(p<0.001, n=9)$. The concentration of $R B C$ to iontophoresis of noradrenaline was lower after a single pulse (black) compared to repeated pulses (blue) $(p=0.04, n=9)$. For acetylcholine red lines indicate curve-fits obtained by nonlinear modelling of the responses. For noradrenaline red lines indicate linear regression lines. Error bars represent mean $\pm S E M$. 


\subsection{The microvascular response to insulin in the skin}

\subsubsection{Experimental design}

By a controlled experimental study, we investigated whether insulin delivered by transdermal iontophoresis increases the microvascular perfusion in the skin. Furthermore, we investigated if the effect is dependent on local synthesis of NO, by pretreating the skin using iontophoresis of L-NAME, compared to control site by iontophoresis of PBS (Figure 3.8).

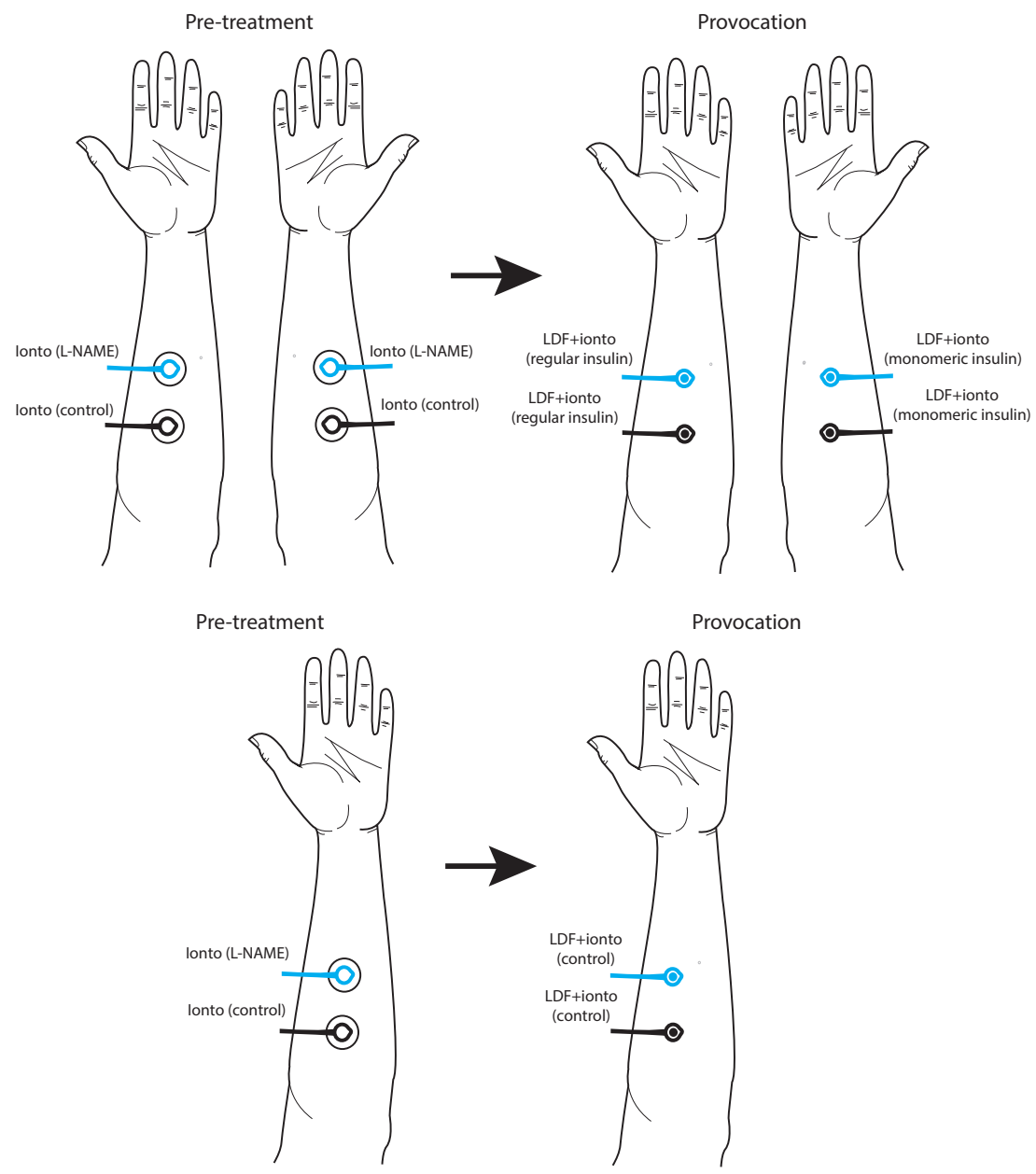

Figure 3.8. Schematic diagram of the experimental setup in study III. The different skin sites used for measurement of microvascular responses after pretreatment followed $(\rightarrow)$ by provocation using iontophoresis (ionto). PBS was used as control solution. Measurements were done using laser Doppler flowmetry (LDF). 


\subsubsection{Results}

Iontophoretic delivery of the control solution (PBS) induced a significant increase in skin perfusion, compared to baseline measurements at both the L-NAME and at the PBS pretreated site $(\mathrm{p}=0.02)$, with no observed difference between the sites $(\mathrm{p}>0.99)$.

When regular insulin was delivered, after pretreatment with L-NAME to inhibit NOS, no difference in skin perfusion was observed compared to when the control solution was delivered $(p=0.15)$. Without NOS inhibition, regular insulin induced a significantly higher perfusion response compared to the control solution $(p=0.03)$.

At the sites where NOS was inhibited, delivery of monomeric insulin did not cause a significant increase in perfusion compared to the control solution $(p=0.22)$, while at sites where NOS was not inhibited the increase in perfusion was stronger after iontophoresis of monomeric insulin compared to control solution $(\mathrm{p}=0.03)$.

The maximum perfusion observed after delivery of regular insulin was not significantly different at the L-NAME pretreated sites compared to sites that were pretreated with the control solution, although a tendency could be observed $(p=0.08)$. The maximum perfusion response to monomeric insulin was significantly reduced at sites where NOS was inhibited compared with the control sites $(\mathrm{p}=0.01)$ (Figure 3.9).

\section{Regular insulin}

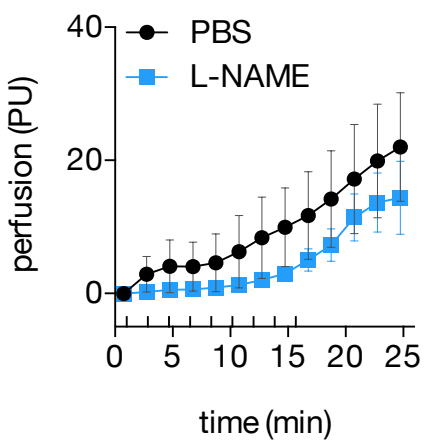

Monomeric insulin

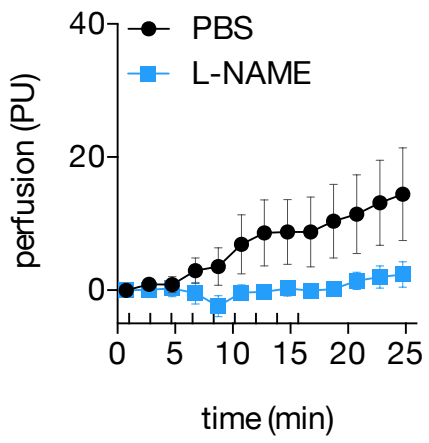

Control (PBS)

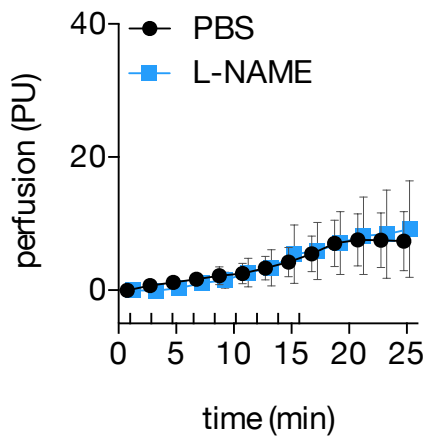

Figure 3.9. Mean blood flow responses to iontophoresis of regular insulin (left), monomeric insulin (middle), and the control solution PBS (right) after pretreatment of the skin by the NO synthase inhibitor L-NAME (blue) or by PBS (black). $n=11$. Error bars represent mean $\pm S E M$.

Iontophoresis current pulses are indicated by upward tick marks along the horizontal axis. 


\subsection{Microvascular and metabolic effects of insulin in the skin}

\subsubsection{Experimental design}

In the fourth study the effects of insulin on glucose metabolism and microvascular blood flow in the skin were investigated. Microdialysis was used to deliver insulin to the skin and to measure changes in tissue concentrations of glucose, lactate and pyruvate. A systemic physiological increase in glucose and insulin concentrations was then induced by an oral glucose load. Microvascular blood flow in the tissue surrounding the microdialysis catheters was simultaneously assessed by the urea clearance technique and by LSCI (Figure 3.10).

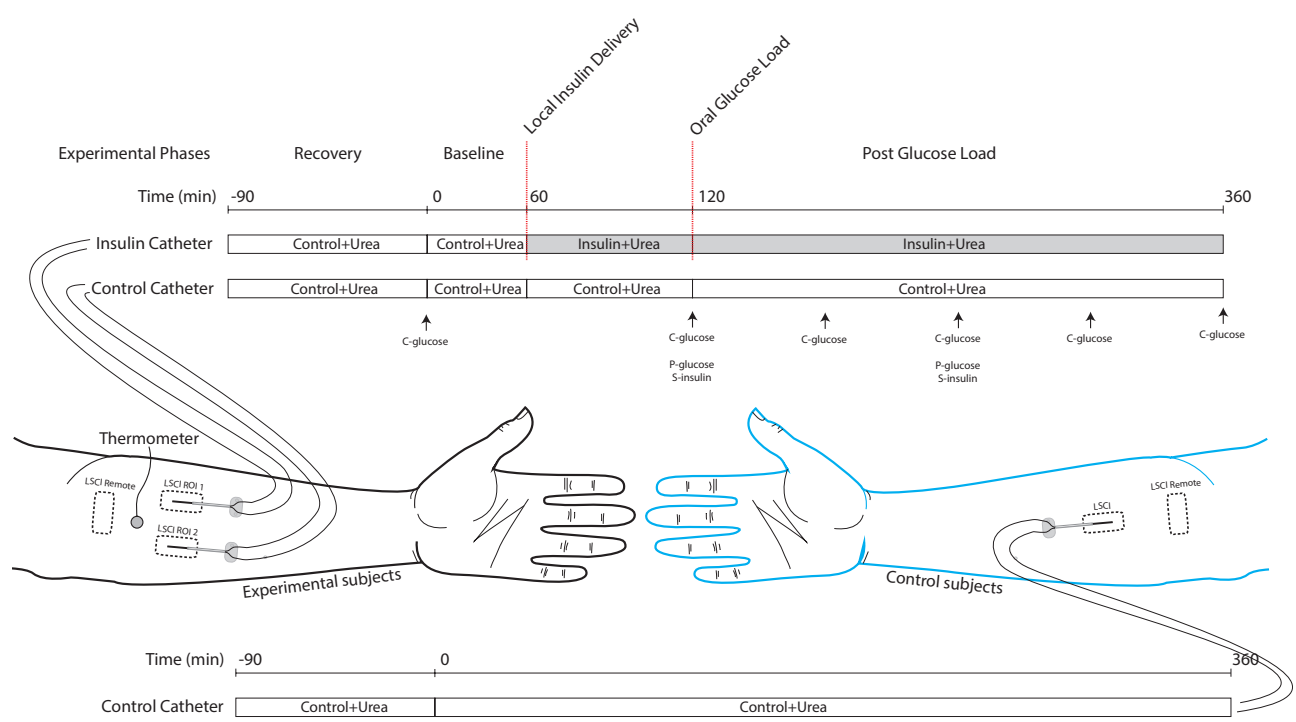

Figure 3.10. Experimental protocol and schematic diagram of the setup in study $I V$. The different skin sites used for measurement of microvascular and metabolic responses to provocations. Measurements were done using microdialysis and laser speckle contrast imaging (LSCI). The arm to the left represents the experimental protocol and the arm to the right represents the control subjects who did not receive intradermal insulin delivery or an oral glucose load. 


\subsubsection{Results}

In control subjects who were not given an oral glucose load, no change in glucose $(p=0.37)$, lactate $(p=0.69)$ or pyruvate $(p=0.39)$ was observed during the experiment. No significant change in urea concentration were observed $(p=0.43)$, although a tendency of decrease was observed over time. LSCI measured a significant increase in perfusion surrounding the microdialysis catheters, compared to a non-affected remote skin site.

Local delivery of insulin increased skin blood flow (urea clearance, $p=0.047$ ) and perfusion (LSCI, $\mathrm{p}=0.002$ ) (Figure 3.11), paralleled by increases in pyruvate $(\mathrm{p}=0.01)$ and lactate $(\mathrm{p}=0.04)$ (Figure 3.12), although no change was observed for glucose $(p=0.97)$.

After the oral glucose load a similar increase in urea clearance was measured in both the microdialysis catheter perfused with insulin and the control catheter. After the oral glucose load perfusion measured around both catheters by LSCI increased significantly after 1 and 2 hours compared to baseline values $(\mathrm{p}<0.001)$. Except for a significantly higher pyruvate and lactate concentration in the insulin catheter at the time of the oral glucose load intake ( $p<0.001$ ), there were no significant differences between the insulin and control catheter regarding glucose, pyruvate and lactate. The interstitial glucose concentration peaked between 53-83 minutes after oral intake of glucose, with no significant difference between the insulin and the control catheter (Figure 3.13).
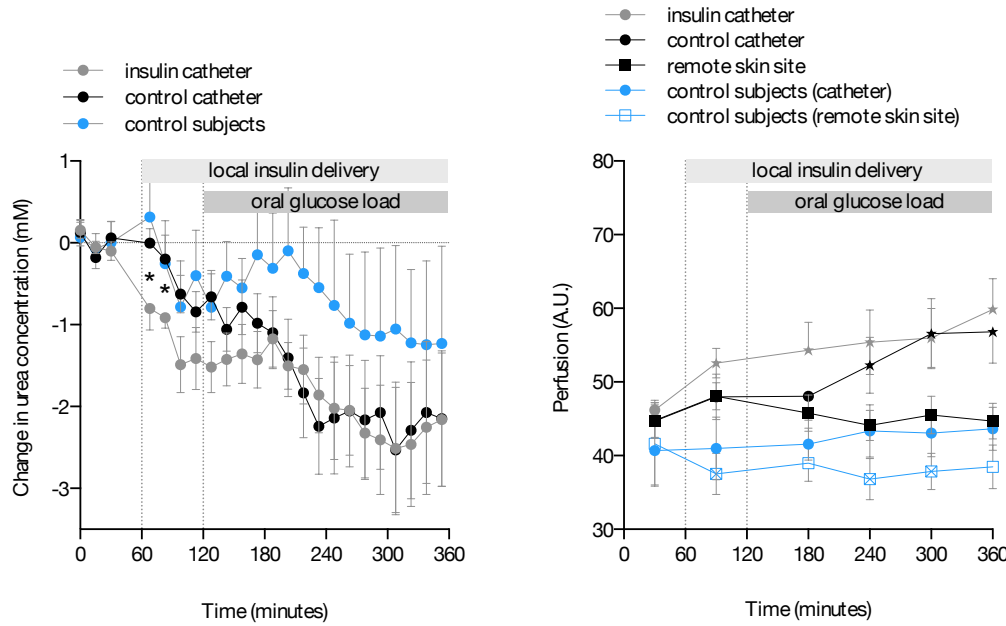

Figure 3.11. Changes in local skin blood flow measured by urea clearance (left) and laser speckle contrast imaging (right), during local insulin delivery and after an oral glucose load. Grey markers indicate intradermal delivery of insulin and black markers indicate intradermal delivery of the control substance $(n=8)$. A separate group of 6 subjects (blue markers) did not receive intradermal insulin delivery or an oral glucose load. Error bars represent mean $\pm S E M . *$ indicates a significant difference between the insulin and control catheter. $\star$ indicates a significant change from baseline. 

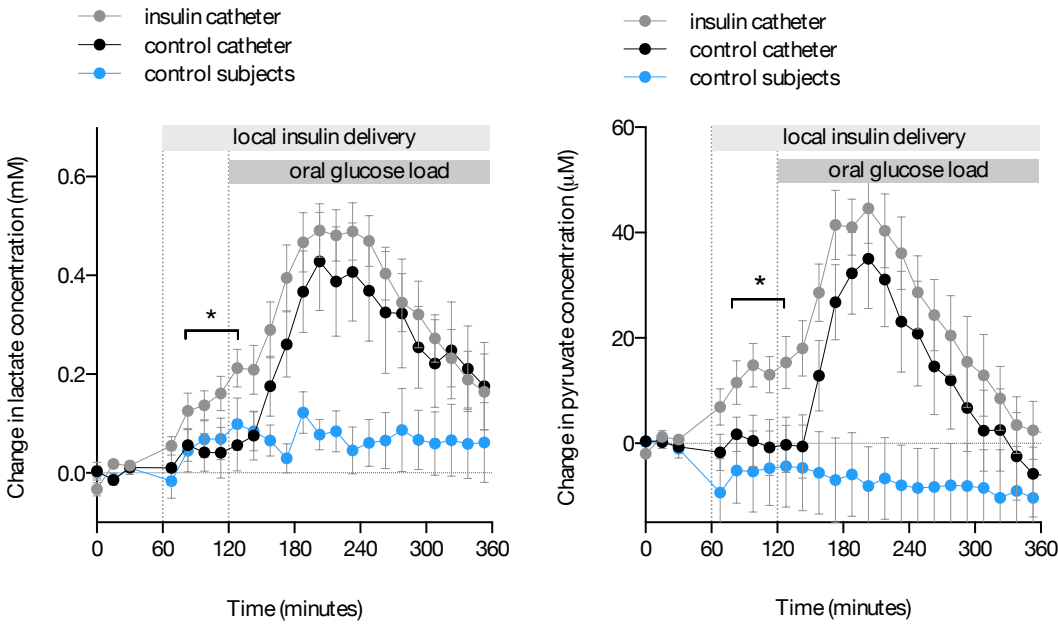

Figure 3.12. Changes in interstitial lactate (left) and pyruvate (right) during local insulin delivery and after an oral glucose load. Grey markers indicate intradermal delivery of insulin and black markers indicate intradermal delivery of the control substance $(n=8)$. A separate group $(n=6$, blue markers) did not receive intradermal insulin delivery or an oral glucose load. Error bars represent mean \pm SEM. * indicates a significant difference between the insulin and control catheter.

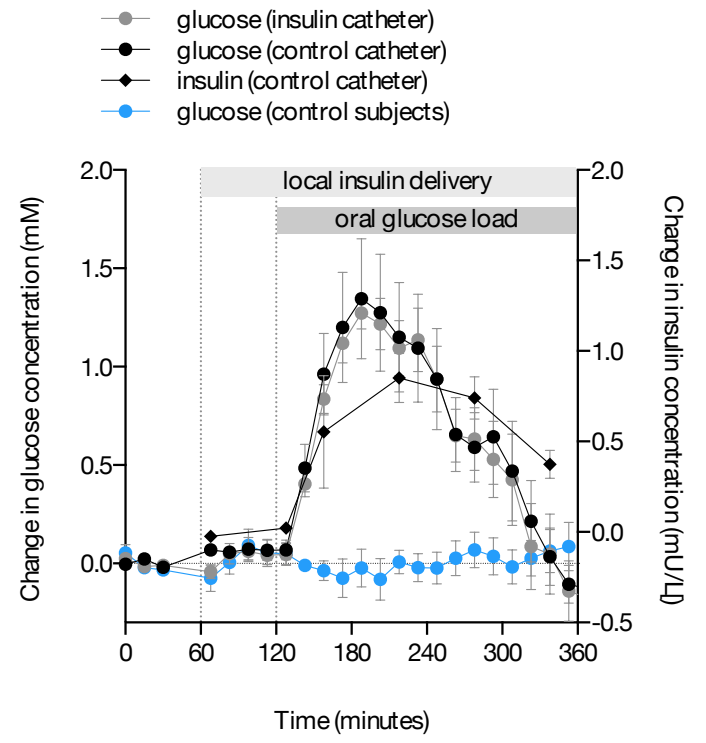

Figure 3.13. Changes in interstitial glucose (circles) and insulin (diamonds) in the skin during intradermal insulin delivery (grey markers) or a control substance (black markers), and after an oral glucose load $(n=8)$. A separate group (blue markers, $n=6$ ) did not receive intradermal insulin delivery or an oral glucose load. Error bars represent mean \pm SEM. 


\section{Discussion}

In this thesis several measurement techniques and provocations have been combined in order to study metabolic and vascular responses in the human skin. Some important methodological aspects of these measurement methods and provocations have been investigated. Also, the microvascular effects of insulin in the skin as well as its effect on skin metabolism have been studied.

An important advantage of doing experiments in peripheral tissues, and in particular in the skin is that systemic side-effects of the provocation that may confound the results or pose a risk for the test subjects, can usually be completely avoided. When non-invasive or at least minimally invasive techniques are used, local side effects can also be reduced, which makes experiments safer and easier to carry out in healthy volunteers and patients.

During recent years, the microcirculation of the skin has emerged as a valuable model of the microcirculation in other organs and tissues, including muscle (Holowatz et al, 2008). The response of the cutaneous microvasculature to locally delivered ACh has been used extensively as a measure of endothelial function, and impaired responses in the skin have been related to a number of systemic diseases, including heart failure (Tesselaar et al, 2012), diabetes mellitus (Morris et al, 1995) and hypertension (Farkas et al, 2004). Also, a number of studies have reported a stimulatory effect of locally delivered insulin on microvascular perfusion and vasomotion in the skin (de Jongh et al, 2008; Rossi et al, 2005a). Furthermore, it has been demonstrated that systemic hyperinsulinemia is capable of increasing the number of perfused capillaries in the skin (de Jongh et al, 2004b; Serne et al, 2002).

At the same time, care should be taken when generalizing the results obtained from measurements in the skin. Although microvascular measures in skin have shown a good correlation with cardiovascular risk factors in some studies, other studies have found that impaired microvascular responses are not uniformly distributed between different vascular beds (Baggia et al, 1997; Gutterman et al, 2016; Haltmayer et al, 2001).

\subsection{Measurement of skin microcirculation}

Since the skin is being used more and more as a tissue in which microvascular studies are done, it is important to use appropriate techniques for measurement of microvascular responses. An advantage when studying the microcirculation of the skin is that non-invasive, optical techniques, can be used. The results from Study I suggest that all the techniques that were studied can accurately detect the vasodilatory response during iontophoresis of SNP. TiVi, which is based on the principle of measuring RBC 
concentration, was however more sensitive than LSCI in measuring vasoconstriction in the skin after iontophoresis of NA.

The difference in sensitivity of the measurement techniques could be explained by fundamental differences in which aspect of the microcirculation that is measured. Vasoconstriction is the result of a contraction of the smooth muscle cells in the vessel wall. During vasoconstriction the diameter of the lumen decreases which theoretically can result in increased blood flow, but decreased $\mathrm{RBC}$ concentration. TiVi is only sensitive to changes in the RBC concentration, while LSCI and LDF measure perfusion, which is the product of $\mathrm{RBC}$ concentration and $\mathrm{RBC}$ velocity. Thus, LDF is possibly unable to detect vasoconstriction due to a simultaneous increase in $\mathrm{RBC}$ velocity. Another explanation is that the vasoconstriction after iontophoresis of NA causes the laser light to penetrate deeper into the skin where the impact on perfusion could be smaller. A third possible explanation is that the basal blood of the skin is close to the "biological zero" (Lipnicki \& Drummond, 2001) and the LDF technique lacks the required sensitivity to measure a further decrease in perfusion.

In agreement with a previous study (Puissant et al, 2013), it was found that the image-based techniques, and in particular LSCI, have a lower inter-subject variability compared with LDF. The reproducibility of techniques is important to consider as it impacts on the number of subjects needed to obtain adequate statistical power. LDF has been found to have relatively poor reproducibility in previous studies as well (Cracowski et al, 2006), although standardising the site of measurement improves the reproducibility (Kubli et al, 2000). Thus, the use of image-based techniques may improve the quality of microvascular studies in the skin by lowering site-to-site and intersubject variability. This was one of the reasons to use LSCI instead of LDF in Study IV, where the microvascular effects on insulin were studied using microdialysis. Another reason was that the drugs were administered by a microdialysis catheter with a membrane length of $10 \mathrm{~mm}$. Using the image-based technique increased the probability of detecting local microvascular effects surrounding the catheter, as the drug distribution and the microvascular response, is not necessarily uniform around the catheter membrane.

\subsection{Analysing dynamics of skin perfusion}

The local response measured in skin after drug delivery depends on various factors including the method of delivery, the rate of drug delivery, the dosage, the clearance from skin and the local metabolism of the compartment studied. Interpretation of drug responses during iontophoresis is hampered by the fact that the delivered dose is unknown. Analysis of the dynamics of the response may however in iontophoresis studies help to indirectly understand the local metabolism and clearance of the delivered drug. On the other hand, with microdialysis, the concentration of drugs in the perfusate 
and dialysate can be measured to estimate the delivered dose, although some uncertainties still remain as molecules can adhere to the surface of the plastic tubing and the catheter membrane.

The estimation of perfusion half-life was used in Study II to describe the pharmacodynamics of ACh and MCh in the skin. The perfusion half-life of MCh was longer compared to $\mathrm{ACh}$, both drugs inducing a comparable maximum response. The results could be explained by the difference in degradation by acetylcholinesterase (AChE). A possible involvement of AChE may also be one explanation to why repetitive administration by iontophoresis of $\mathrm{ACh}$ resulted in a more rapid decrease of perfusion with each consecutive pulse. The use of AChE inhibitors, such as neostigmine, could help to further elucidate the underlying mechanism. Another explanation to the consecutive decrease in estimated perfusion half-life after repetitive delivery of $\mathrm{ACh}$ is a decrease in electrical resistance of the skin as an effect by the iontophoresis current. The iontophoresis current has been claimed to open pores in the skin that decrease electrical resistance and facilitate drug transport (Cullander, 1992).

Today there is no general consensus regarding the analyses of blood flow responses during iontophoresis of vasoactive drugs. There has been a tradition during iontophoresis experiments to mainly interpret data measured during the provocation with focus on the maximum response or area under the curve (Tesselaar \& Sjoberg, 2011). The maximum response may however not represent the physiological maximum response, and by neglecting the rest of the response, such as the effect after the drug delivery, important physiological aspects may be overlooked. By considering the recovery period after iontophoretic drug delivery, drug metabolism and clearance can be further investigated.

\subsection{Microvascular and metabolic actions of insulin in the skin}

No previous study has investigated through which mechanisms local delivery of insulin to the skin causes vasodilation. In study III the aim was therefore to determine if the vasodilation observed is mediated by NO.

The results from the study showed that although part of the perfusion increase after delivery of regular insulin could be blocked using L-NAME, the effect was not significant. A possible explanation is that iontophoresis of regular insulin results in substantial non-specific vasodilation. This has been observed in previous iontophoresis studies as well, and complicates the interpretation of the microvascular responses to the insulin itself (Montero et al, 2014; Serne et al, 2002). On the other hand, it was found that the vasodilatory response to monomeric insulin in the skin, although it was weaker than regular insulin, could be completely blocked by inhibition of NOS. Monomeric insulin has previously been found to more easily penetrate the skin, presumably due to 
its smaller molecular size. Monomeric insulin also has an increased electrical charge at $\mathrm{pH}$ levels encountered in the skin (Langkjaer et al, 1998). It is therefore likely that iontophoretic delivery of monomeric insulin is more effective than regular insulin and causes less non-specific effects.

In Study IV, the metabolic and microvascular responses to insulin in the skin were investigated using microdialysis. The strength of the microdialysis technique in studying tissue metabolism and microcirculation is the opportunity of a high temporal resolution, which makes it possible to assess dynamics of tissue responses. After local delivery of insulin to the skin, an increase in interstitial lactate and pyruvate was measured within the first 15 minutes, although the interstitial glucose concentration was not significantly changed. This is in contrast with previous studies, in which insulin was administered to muscle and a glucose decrease was observed (Chiu et al, 2008; Rosdahl et al, 2000). One explanation to why we did not observe a decrease in glucose in the skin, could be a rapid glucose supply from to the vasculature to the tissue, that may have been facilitated by insulin-mediated vasodilation.

After the oral glucose load a peak in interstitial glucose was measured between 53 and 83 minutes, while interstitial pyruvate and lactate peaked between 68 and 98 , with no significant changes between the insulin catheter and control catheter. In a previous study in healthy subjects the peak of interstitial glucose and pyruvate in subcutaneous tissue was measured between 30 and 90 minutes, followed by peak in lactate between 60 and 120 minutes, after an oral glucose load (Rajamand et al, 2005). Future studies measuring the dynamics of skin metabolism with a higher temporal resolution would be of interest.

Both during local delivery of insulin, and during the systemic glucose load, increased blood flow was observed in the skin in parallel with an increase in interstitial insulin. By studying responses in a separate control group, that did not receive an oral glucose load, we could determine that the increase in blood flow was not solely the result of a local trauma effect. At the same time, skin perfusion as measured with LSCI was not increased after the oral glucose load, at the sites remote from the microdialysis catheters. These somewhat contradictory findings can be caused by differences in sensitivity and measurement depth between urea clearance and LSCI. The possibility that part of the urea response was caused by changes in blood flow in subcutaneous adipose tissue cannot be completely ruled out, although we were careful to place the catheters as superficially as possible. However, the findings from study III and IV taken together further add to the evidence that insulin has vasoactive properties effective in the skin, both when given locally and when endogenously released from the pancreas. 


\subsection{Limitations}

The studies have a number of limitations that may have confounded the results or may restrict their generalizability. Some of the most significant limitations will be described here.

The recruitment of all subjects was based on those who confirmed that they want to participate after advertising on the university online advertising site, which might lead to a selection bias. Small groups of subjects were also studied in each experiment increasing the risk of type II error. The subjects were mostly young adults and the findings in these studies should therefore with caution be extrapolated to other age groups, considering the influence of age on microvascular responses (Rossi et al, 2002). Also, few of the experiments in this thesis had an equal distribution of males and females and potential gender differences can therefore not be excluded.

All measurements were done on the volar side of the forearm. There is a known variation in basal perfusion depending on skin site. Lower legs and the side of the trunk have shown low perfusion measured by LDF, while the hands, fingers and face have a higher perfusion (Tur et al, 1983). Also, subjects were in a semi-supine position during the experiments and in study IV this position was maintained during 7.5 hours. A possible impact on blood flow by prolonged resting cannot be excluded and indeed a slight decrease in skin blood flow was measured using LSCI in study IV, remote from the catheters, over the course of the experiment. However, skin temperature did not decrease.

In study I, experiment 2 and 3, different skin sites were used for LDF than for the image-based techniques, because it was impossible to measure responses simultaneously with the three techniques at the same skin site. However, the measurement sites were chosen near each other on the same forearm.

In study II, MCh was used to study the metabolism of $\mathrm{ACh}$, since $\mathrm{MCh}$ is not metabolised by AChE. Possibly, AChE inhibitors instead could have been delivered by iontophoresis as a pretreatment to directly study the local effect of $\mathrm{AChE}$ on the blood flow response during and after iontophoresis of $\mathrm{ACh}$.

In study III, PBS was used as control solution for both L-NAME and insulin. It has historically been hard to find proper control solutions for insulin in iontophoresis experiments. In previous studies $0.9 \%$ saline has been used as control solutions for regular insulin (Humulin R) (Montero et al, 2014; Rossi et al, 2005a). However, Humulin R contains zinc-insulin crystals dissolved in clear fluid, glycerol, metacresol and water for injection. Unfortunately, we were not either able to obtain the diluting medium of Humulin. Insulin aspart (Novorapid) contains, except insulin, glycerol, metacresol, phenol, disodium phosphate, dihydrate and water for injection. Studies where the original diluting medium has been used as control solution (Serne et al, 2002) 
can therefore be considered more reliable. Another limitation of study III was that only the NO-dependency was investigated and any potential involvement of local sensory nerves could have been masked as a result of the pre-treatment with EMLA. The role of ET-1 was not studied either, although ET-1 probably has an important role in the local actions of insulin (Kim et al, 2006). The study design could have been improved by pretreatment by other antagonists and by different doses of L-NAME or insulin to investigate a dose-dependency in the vasodilatory effect. The results nevertheless indicate that the main component of the vasodilatory actions of insulin in the skin is NO-dependent.

In study IV, the depth of the microdialysis catheter was not verified. Since conclusion is drawn regarding the skin response, it is of great importance that we actually measured in the skin. Since the diameter of the microdialysis membrane is 0.6 $\mathrm{mm}$ and the dermal layer of the forearm is approximately $1 \mathrm{~mm}$, there is a risk that some part of the membrane has been in contact with the underlying subcutaneous tissue. A previous experiment by our group however confirms, using the same insertion technique, an intradermal position with a mean depth of $0.78 \pm 0.23 \mathrm{~mm}$, measured by ultrasound device (Samuelsson et al, 2012).

Because of the insensitivity of the ELISA assay for insulin aspart, the concentration of the locally delivered insulin in study IV could not be determined in the microdialysate. Considering that the added concentration in the perfusate $(16.7 \mathrm{mU} / \mathrm{mL})$ was several orders of magnitude higher than the fasting serum insulin concentration $(0.007 \mathrm{mU} / \mathrm{L})$, the locally delivered doses of insulin may however be considered as supraphysiological.

In study IV local blood flow was indirectly assessed by urea clearance, a recently presented technique for tissue blood flow monitoring (Farnebo et al, 2011), that has not found widespread application. An alternative would have been the more established ethanol clearance technique. The principle is the same as with urea clearance in that ethanol added to the perfusate will diffuse over the membrane of the catheter. The difference in ethanol concentration between the perfusate and dialysate is proportional to tissue blood flow (Hickner et al, 1991; 1992). The urea clearance technique was however used to avoid difficulties associated with the possible evaporation of ethanol. 


\section{Conclusion}

The studies in this thesis have led to the following conclusions:

I LDF, LSCI and TiVi enable measurement of the vasodilation caused by iontophoresis of SNP and PORH. LSCI is more sensitive than LDF and TiVi in measuring microvascular changes during forearm occlusion without prior exsanguination, while TiVi is more sensitive to vasoconstriction induced by NA. LSCI and TiVi show lower inter-subject variability than LDF.

II In skin, iontophoresis of ACh results in a shorter perfusion half-life than $\mathrm{MCh}$, probably as a result of differences in local metabolism. A stronger microvascular response is achieved when ACh or NA is given by iontophoresis using a single pulse as compared to multiple pulses, using the same total charge. The microvascular response to iontophoresis of $\mathrm{ACh}$ changes when it is delivered repeatedly at the same skin site, possibly as a result of changes in skin permeability or drug dynamics.

III Insulin induces vasodilation in the skin. The increase in skin blood flow caused by iontophoresis of monomeric insulin can be suppressed by pretreatment with LNAME, indicating that the vasodilatory actions of insulin in the skin are mediated by the release of nitric oxide.

IV Local delivery of insulin to the skin by microdialysis results in increased interstitial pyruvate and lactate levels indicating an increased glucose metabolism, paralleled by an increase in skin blood flow as measured by LSCI and microdialysis urea clearance. An oral glucose load increases interstitial insulin and glucose levels in the skin, paralleled by an increase in blood flow as measured by microdialysis urea clearance. 


\section{Future perspectives}

What we know today regarding the correlation between skin microvascular responses and cardiovascular risk factors, is that measurements from the skin can be used as prognostic biomarkers rather than diagnostic biomarkers (Hellmann et al, 2015). Improved understanding of the pathophysiology and linkage between skin response to disease may successively lead to improved prognostics and potential diagnostic tools. One effort to this is the Swedish CardioPulmonary bioImage Study (SCAPIS), which prospectively will study a Swedish cohort with the aim of improving the risk prediction of cardiopulmonary diseases, one factor of the study being measurements of skin microvascular responses.

Giving drugs locally in the skin and measuring their responses without risking systemic effects, could be a valuable model for the pharmaceutical industry, where large number of drug candidates need to be investigated. Iontophoresis and microdialysis, combined with local measurement of microvascular and metabolic responses, could thus be used to early assess the tolerability and suitability of drug candidates in humans.

It is concluded in this thesis that insulin has a NO-dependent vasodilatory action in the skin. A next step will be to investigate the potential involvement of ET-1 by use of endothelin receptor antagonist in healthy subjects, followed by studies in patient groups with obesity and insulin resistance. The ambition is to further elucidate the local mechanisms and effects of insulin and pathophysiological linkage with cardiovascular risk factors. 


\section{Acknowledgements}

The research of this thesis was financially supported by Linköping University, ALF grants, Östergötland County Council and The Grönberg Foundation, which are gratefully acknowledged.

I wish to express my sincere gratitude to all those who in different ways have supported, inspired and contributed to the completion of this thesis. Especially I would like to express my gratitude to:

First of all, my supervisor associate professor Erik Tesselaar. Thank you for your mentoring by enthusiasm, guidance along the way, believing in me and allowing me to grow as a scientist.

My assistant supervisors; professor Folke Sjöberg, for introducing me to the world of research and your amazing optimism, and associate professor Simon Farnebo for valuable help and support.

Alexandra Högstedt and Robin Mirdell for providing a stimulating atmosphere in our research group and accurate analysis during our journal clubs. Max Bergkvist and Johan Zötterman for good collaboration. I wish you all the best of luck with your thesis projects!

Joakim Henricson for your kindness and hands-on support through the project.

Students that have contributed to the thesis by their projects and work. Thank you Saikat Sarker, Veeranjaneyulu Sadda, Liam Ward, Andreas Löfberg and Johannes Hackethal.

The staff at the Burn Centre of Linköping. Especially I would like to thank Ingrid Steinwall and Ingmarie Jarnhed Andersson for always being positive and facilitating the work, Matilda Karlsson and Sara Bergstrand for help with venous blood sampling and Benjamin Grossmann.

Florence Sjögren for deep methodological knowledge and help with drug preparations.

The staff at the Centre for Teaching and Research in Disaster Medicine and Traumatology (KMC) in Linköping. For you believing in me and let me be inspired by your work when I was new in Linköping. Dan Linghammar, Maria Lampi, Henrik Lidberg and Anders Sandberg.

All the participants in the studies. This thesis could not have been done without you!

All the reviewers of our work, for careful and thorough analysis leading to improvements. 
My dear friends, for filling my life with meaning and pleasure during these years. Thank you; Björn Appelgren, Mattias Rönnerfalk, Fredrik Törnmarck, Peter Karlsson, Hampus Lundgren, Johan Rådman, Alexander Zabala, Christopher Schäfer, Robert Larsen, Henrik Ahnberg, Filip Lindholm and Samuel Crona.

And most importantly, my family. You mean more to me than I can ever put down in writing.

My grandfather Bengt (in memoriam) for your sincere support, love and encouragement.

My grandmother Anna-Stina and uncle Per for always being there and sharing your experience.

Ulla and Bengt, for genuine thoughtfulness.

My brother Henrik, for your down to earth attitude, contagious laugh and invaluable friendship. The best godfather!

My mother Kristina and father Per for unconditional love, endless support and guidance in life. You are my true heroes and I owe everything to you.

My beloved Sofia - the love of my life! For your unbelievable patience, support and love, making this journey possible. I love you!

Julia for being the strongest light of my life! Thank you for blessing me with the perspective of the true importance. 


\section{References}

Anfossi, G., Russo, I., Doronzo, G. \& Trovati, M. (2009) Contribution of insulin resistance to vascular dysfunction. Arch Physiol Biochem, 115(4), 199-217.

Angus, J. A. \& Wright, C. E. (2000) Techniques to study the pharmacodynamics of isolated large and small blood vessels. J Pharmacol Toxicol Methods, 44(2), 395-407.

Antonios, T. F., Singer, D. R., Markandu, N. D., Mortimer, P. S. \& MacGregor, G. A. (1999) Rarefaction of skin capillaries in borderline essential hypertension suggests an early structural abnormality. Hypertension, 34(4 Pt 1), 655-8.

Baggia, S., Perkins, K. \& Greenberg, B. (1997) Endothelium-dependent relaxation is not uniformly impaired in chronic heart failure. J Cardiovasc Pharmacol, 29(3), 38996.

Baron, A. D. (1994) Hemodynamic actions of insulin. Am J Physiol, 267(2 Pt 1), E187202.

Belzowzki, A., Bergren, D., Brugler, A., Hillman, B. G., Hillman, K. C., Hillman, S. R., Kuss, B., Ngo, B. T., Pisarri, T., Rendell, M. S., Thompson, S. L. \& Turner, S. A. (2012) The effect of vasoactive agents on post-pressure hyperemia. Microvasc Res, 84(3), 345-50.

Benfeldt, E., Serup, J. \& Menne, T. (1999) Microdialysis vs. suction blister technique for in vivo sampling of pharmacokinetics in the human dermis. Acta Derm Venereol, 79(5), 338-42.

Benveniste, H. (1989) Brain microdialysis. J Neurochem, 52(6), 1667-79.

Berghoff, M., Kathpal, M., Kilo, S., Hilz, M. J. \& Freeman, R. (2002) Vascular and neural mechanisms of ACh-mediated vasodilation in the forearm cutaneous microcirculation. J Appl Physiol (1985), 92(2), 780-8.

Bergkvist, M., Henricson, J., Iredahl, F., Tesselaar, E., Sjoberg, F. \& Farnebo, S. (2015) Assessment of microcirculation of the skin using Tissue Viability Imaging: A promising technique for detecting venous stasis in the skin. Microvasc Res, 101, 20-5.

Bito, L., Davson, H., Levin, E., Murray, M. \& Snider, N. (1966) The concentrations of free amino acids and other electrolytes in cerebrospinal fluid, in vivo dialysate of brain, and blood plasma of the dog. J Neurochem, 13(11), 1057-67.

Bonner, R. \& Nossal, R. (1981) Model for laser Doppler measurements of blood flow in tissue, Appl Opt. United States, 2097-107.

Braverman, I. M. (2000) The cutaneous microcirculation. J Investig Dermatol Symp Proc, 5(1), 3-9.

Briers, D., Duncan, D. D., Hirst, E., Kirkpatrick, S. J., Larsson, M., Steenbergen, W., Stromberg, T. \& Thompson, O. B. (2013) Laser speckle contrast imaging: theoretical and practical limitations. J Biomed Opt, 18(6), 066018.

Butcher, J. T., Goodwill, A. G., Stanley, S. C. \& Frisbee, J. C. (2013) Blunted temporal activity of microvascular perfusion heterogeneity in metabolic syndrome: a new 
attractor for peripheral vascular disease? Am J Physiol Heart Circ Physiol, 304(4), H547-58.

Chiu, J. D., Richey, J. M., Harrison, L. N., Zuniga, E., Kolka, C. M., Kirkman, E., Ellmerer, M. \& Bergman, R. N. (2008) Direct administration of insulin into skeletal muscle reveals that the transport of insulin across the capillary endothelium limits the time course of insulin to activate glucose disposal. Diabetes, 57(4), 828-35.

Clark, M. G. (2008) Impaired microvascular perfusion: a consequence of vascular dysfunction and a potential cause of insulin resistance in muscle. Am J Physiol Endocrinol Metab, 295(4), E732-50.

Clark, M. G., Rattigan, S., Clerk, L. H., Vincent, M. A., Clark, A. D., Youd, J. M. \& Newman, J. M. (2000) Nutritive and non-nutritive blood flow: rest and exercise. Acta Physiol Scand, 168(4), 519-30.

Clark, M. G., Wallis, M. G., Barrett, E. J., Vincent, M. A., Richards, S. M., Clerk, L. H. \& Rattigan, S. (2003) Blood flow and muscle metabolism: a focus on insulin action. Am J Physiol Endocrinol Metab, 284(2), E241-58.

Clough, G. F., Boutsiouki, P., Church, M. K. \& Michel, C. C. (2002) Effects of blood flow on the in vivo recovery of a small diffusible molecule by microdialysis in human skin. J Pharmacol Exp Ther, 302(2), 681-6.

Cracowski, J. L., Lorenzo, S. \& Minson, C. T. (2007) Effects of local anaesthesia on subdermal needle insertion pain and subsequent tests of microvascular function in human. Eur J Pharmacol, 559(2-3), 150-4.

Cracowski, J. L., Minson, C. T., Salvat-Melis, M. \& Halliwill, J. R. (2006) Methodological issues in the assessment of skin microvascular endothelial function in humans. Trends Pharmacol Sci, 27(9), 503-8.

Cullander, C. (1992) What are the pathways of iontophoretic current flow through mammalian skin? Advanced Drug Delivery Reviews, 9(Issues 2-3), 119-135.

Daly, M. J. \& Henry, R. E. (1980) Quantitative measurement of skin perfusion with xenon-133. J Nucl Med, 21(2), 156-60.

de Jongh, R. T., Serne, E. H., IJzerman, R. G., de Vries, G. \& Stehouwer, C. D. (2004a) Free fatty acid levels modulate microvascular function: relevance for obesity-associated insulin resistance, hypertension, and microangiopathy, Diabetes. United States, 287382.

de Jongh, R. T., Serne, E. H., IJzerman, R. G., de Vries, G. \& Stehouwer, C. D. (2004b) Impaired microvascular function in obesity: implications for obesity-associated microangiopathy, hypertension, and insulin resistance. Circulation, 109(21), 2529-35.

de Jongh, R. T., Serne, E. H., IJzerman, R. G., Jorstad, H. T. \& Stehouwer, C. D. (2008) Impaired local microvascular vasodilatory effects of insulin and reduced skin microvascular vasomotion in obese women. Microvasc Res, 75(2), 256-62.

Davignon, J. \& Ganz, P. (2004) Role of endothelial dysfunction in atherosclerosis. Circulation 109, III27-III32. 
Delgado, J. M., DeFeudis, F. V., Roth, R. H., Ryugo, D. K. \& Mitruka, B. M. (1972) Dialytrode for long term intracerebral perfusion in awake monkeys. Arch Int Pharmacodyn Ther, 198(1), 9-21.

Desvigne, N., Barthelemy, J. C., Frere, D., Gay-Montchamp, J. P. \& Costes, F. (2005) Microdialysis of insulin-like growth factor-I in human muscle. Eur J Appl Physiol, 94(1-2), 216-9.

Dreyfuss, C., Wauters, A., Adamopoulos, D., Pochet, S., Azarkan, M., Berkenboom, G., van de Borne, P. \& Argacha, J. F. (2013) L-NAME iontophoresis: a tool to assess NO-mediated vasoreactivity during thermal hyperemic vasodilation in humans. $J$ Cardiovasc Pharmacol, 61(5), 361-8.

Droog, E. J. \& Sjoberg, F. (2003) Nonspecific vasodilatation during transdermal iontophoresis-the effect of voltage over the skin. Microvasc Res, 65(3), 172-8.

Duckworth, W. C., Bennett, R. G. \& Hamel, F. G. (1998) Insulin degradation: progress and potential. Endocr Rev, 19(5), 608-24.

Eringa, E. C., Stehouwer, C. D., Merlijn, T., Westerhof, N. \& Sipkema, P. (2002) Physiological concentrations of insulin induce endothelin-mediated vasoconstriction during inhibition of NOS or PI3-kinase in skeletal muscle arterioles. Cardiovasc Res, 56(3), 464-71.

Eringa, E. C., Stehouwer, C. D., Roos, M. H., Westerhof, N. \& Sipkema, P. (2007) Selective resistance to vasoactive effects of insulin in muscle resistance arteries of obese Zucker (fa/fa) rats. Am J Physiol Endocrinol Metab, 293(5), E1134-9.

Farkas, K., Kolossvary, E., Jarai, Z., Nemcsik, J. \& Farsang, C. (2004) Non-invasive assessment of microvascular endothelial function by laser Doppler flowmetry in patients with essential hypertension, Atherosclerosis. Ireland, 97-102.

Farnebo, S., Samuelsson, A., Henriksson, J., Karlander, L. E. \& Sjoberg, F. (2010a) Urea clearance: a new method to register local changes in blood flow in rat skeletal muscle based on microdialysis. Clin Physiol Funct Imaging, 30(1), 57-63.

Farnebo, S., Thorfinn, J., Henricson, J. \& Tesselaar, E. (2010b) Hyperaemic changes in forearm skin perfusion and RBC concentration after increasing occlusion times. Microvasc Res, 80(3), 412-6.

Farnebo, S., Zettersten, E. K., Samuelsson, A., Tesselaar, E. \& Sjoberg, F. (2011) Assessment of blood flow changes in human skin by microdialysis urea clearance. Microcirculation, 18(3), 198-204.

Feelisch, M. (1998) The use of nitric oxide donors in pharmacological studies. Naunyn Schmiedebergs Arch Pharmacol, 358(1), 113-22.

Ferrannini, E. \& Mari, A. (1998) How to measure insulin sensitivity. J Hypertens, 16(7), 895-906.

Folkesson, K. T., Samuelsson, A., Tesselaar, E., Dahlstrom, B. \& Sjoberg, F. (2012) A human vascular model based on microdialysis for the assessment of the vasoconstrictive dose-response effects of norepinephrine and vasopressin in skin. Microcirculation, 19(4), 352-9. 
Fredriksson, I., Larsson, M., Nystrom, F. H., Lanne, T., Ostgren, C. J. \& Stromberg, T. (2010) Reduced arteriovenous shunting capacity after local heating and redistribution of baseline skin blood flow in type 2 diabetes assessed with velocity-resolved quantitative laser Doppler flowmetry. Diabetes, 59(7), 1578-84.

Furchgott, R. F. \& Zawadzki, J. V. (1980) The obligatory role of endothelial cells in the relaxation of arterial smooth muscle by acetylcholine. Nature, 288(5789), 373-6.

Gawkrodger, D.J. \& Ardern-Jones, M. R. (2012), Dermatology: An Illustrated Colour Text, 5E, Churchill Livingstone Elsevier, ISBN: 978-0-7020-4449-6. Chapter 1, page: $2-7$.

Grossmann, M., Jamieson, M. J., Kellogg, D. L., Jr., Kosiba, W. A., Pergola, P. E., Crandall, C. G. \& Shepherd, A. M. (1995) The effect of iontophoresis on the cutaneous vasculature: evidence for current-induced hyperemia. Microvasc Res, 50(3), 444-52.

Gutterman, D. D., Chabowski, D. S., Kadlec, A. O., Durand, M. J., Freed, J. K., AitAissa, K. \& Beyer, A. M. (2016) The Human Microcirculation: Regulation of Flow and Beyond. Circ Res, 118(1), 157-72.

Haltmayer, M., Mueller, T., Horvath, W., Luft, C., Poelz, W. \& Haidinger, D. (2001) Impact of atherosclerotic risk factors on the anatomical distribution of peripheral arterial disease. Int Angiol, 20(3), 200-7.

Heinemann, L. (2003) Continuous glucose monitoring by means of the microdialysis technique: underlying fundamental aspects. Diabetes Technol Ther, 5(4), 545-61.

Heitzer, T., Brockhoff, C., Mayer, B., Warnholtz, A., Mollnau, H., Henne, S., Meinertz, T. \& Munzel, T. (2000) Tetrahydrobiopterin improves endothelium-dependent vasodilation in chronic smokers : evidence for a dysfunctional nitric oxide synthase. Circ Res, 86(2), E36-41.

Hellmann, M., Roustit, M. \& Cracowski, J. L. (2015) Skin microvascular endothelial function as a biomarker in cardiovascular diseases? Pharmacol Rep, 67(4), 803-10.

Helmstadter, A. (2001) The history of electrically-assisted transdermal drug delivery ("iontophoresis"). Pharmazie, 56(7), 583-7.

Henricson, J., Tesselaar, E., Persson, K., Nilsson, G. \& Sjoberg, F. (2007) Assessment of microvascular function by study of the dose-response effects of iontophoretically applied drugs (acetylcholine and sodium nitroprusside)--methods and comparison with in vitro studies. Microvasc Res, 73(2), 143-9.

Hickner, R. C., Bone, D., Ungerstedt, U., Jorfeldt, L. \& Henriksson, J. (1994) Muscle blood flow during intermittent exercise: comparison of the microdialysis ethanol technique and 133Xe clearance. Clin Sci (Lond), 86(1), 15-25.

Hickner, R. C., Rosdahl, H., Borg, I., Ungerstedt, U., Jorfeldt, L. \& Henriksson, J. (1991) Ethanol may be used with the microdialysis technique to monitor blood flow changes in skeletal muscle: dialysate glucose concentration is blood-flow-dependent. Acta Physiol Scand, 143(3), 355-6. 
Hickner, R. C., Rosdahl, H., Borg, I., Ungerstedt, U., Jorfeldt, L. \& Henriksson, J. (1992) The ethanol technique of monitoring local blood flow changes in rat skeletal muscle: implications for microdialysis. Acta Physiol Scand, 146(1), 87-97.

Hodges, G. J., Zhao, K., Kosiba, W. A. \& Johnson, J. M. (2006) The involvement of nitric oxide in the cutaneous vasoconstrictor response to local cooling in humans. $J$ Physiol, 574(Pt 3), 849-57.

Hohberg, C., Forst, T., Larbig, M., Safinowski, M., Diessel, S., Hehenwarter, S., Weber, M. M., Schondorf, T. \& Pfutzner, A. (2008) Effect of insulin glulisine on microvascular blood flow and endothelial function in the postprandial state. Diabetes Care, 31(5), 1021-5.

Holowatz, L. A., Thompson-Torgerson, C. S. \& Kenney, W. L. (2008) The human cutaneous circulation as a model of generalized microvascular function. $J$ Appl Physiol (1985), 105(1), 370-2.

Horiuchi, Y., Droog, E. J., Henricson, J., Wikstrom, T., Lennquist, S. \& Sjoberg, F. (2004) Role of histamine release in nonspecific vasodilatation during anodal and cathodal iontophoresis. Microvasc Res, 67(2), 192-6.

IJzerman, R. G., Serne, E. H., van Weissenbruch, M. M., de Jongh, R. T. \& Stehouwer, C. D. (2003) Cigarette smoking is associated with an acute impairment of microvascular function in humans. Clin Sci (Lond), 104(3), 247-52.

Jonk, A. M., Houben, A. J., Schaper, N. C., de Leeuw, P. W., Serne, E. H., Smulders, Y. M. \& Stehouwer, C. D. (2011) Meal-related increases in microvascular vasomotion are impaired in obese individuals: a potential mechanism in the pathogenesis of obesityrelated insulin resistance, Diabetes Care. United States, S342-8.

Kellogg, D. L., Jr. (2006) In vivo mechanisms of cutaneous vasodilation and vasoconstriction in humans during thermoregulatory challenges. J Appl Physiol (1985), 100(5), 1709-18.

Khan, F., Davidson, N. C., Littleford, R. C., Litchfield, S. J., Struthers, A. D. \& Belch, J. J. (1997) Cutaneous vascular responses to acetylcholine are mediated by a prostanoiddependent mechanism in man. Vasc Med, 2(2), 82-6.

Kim, J. A., Montagnani, M., Koh, K. K. \& Quon, M. J. (2006) Reciprocal relationships between insulin resistance and endothelial dysfunction: molecular and pathophysiological mechanisms. Circulation, 113(15), 1888-904.

Kimura, K., Takeuchi, H., Yuri, K. \& Wakayama, I. (2013) Effects of nitric oxide synthase inhibition on cutaneous vasodilation in response to acupuncture stimulation in humans. Acupunct Med, 31(1), 74-80.

Kubli, S., Waeber, B., Dalle-Ave, A. \& Feihl, F. (2000) Reproducibility of laser Doppler imaging of skin blood flow as a tool to assess endothelial function. $J$ Cardiovasc Pharmacol, 36(5), 640-8.

Kubota, T., Kubota, N. \& Kadowaki, T. (2013) The role of endothelial insulin signaling in the regulation of glucose metabolism. Rev Endocr Metab Disord, 14(2), 207-16. 
Langkjaer, L., Brange, J., Grodsky, G. M. \& Guy, R. H. (1998) Iontophoresis of monomeric insulin analogues in vitro: effects of insulin charge and skin pretreatment. $J$ Control Release, 51(1), 47-56.

Lanting, S. M., Johnson, N. A., Baker, M. K., Caterson, I. D. \& Chuter, V. H. (2016) The effect of exercise training on cutaneous microvascular reactivity: A systematic review and meta-analysis. $J$ Sci Med Sport.

Lassen, N. A., Lindbjerg, J. \& Munck, O. (1964) Measurement of blood-flow through skeletal muscle by intramuscular injection of xenon-133. Lancet, 1(7335), 686-9.

Levy, B. I., Ambrosio, G., Pries, A. R. \& Struijker-Boudier, H. A. (2001) Microcirculation in hypertension: a new target for treatment? Circulation, 104(6), 73540 .

Levy, B. I., Schiffrin, E. L., Mourad, J. J., Agostini, D., Vicaut, E., Safar, M. E. \& Struijker-Boudier, H. A. (2008) Impaired tissue perfusion: a pathology common to hypertension, obesity, and diabetes mellitus. Circulation, 118(9), 968-76.

Lindpointner, S., Korsatko, S., Kohler, G., Kohler, H., Schaller, R., Schaupp, L., Ellmerer, M., Pieber, T. R. \& Regittnig, W. (2010) Glucose levels at the site of subcutaneous insulin administration and their relationship to plasma levels. Diabetes Care, 33(4), 833-8.

Lipnicki, D. M. \& Drummond, P. D. (2001) Facilitating laser Doppler measurements of cutaneous adrenergic vasoconstriction: a comparison of methods. Clin Auton Res, 11(2), 93-8.

Lorenzo, S. \& Minson, C. T. (2007) Human cutaneous reactive hyperaemia: role of BKCa channels and sensory nerves. J Physiol, 585(Pt 1), 295-303.

Maley, M. J., House, J. R., Tipton, M. J. \& Eglin, C. M. (2015) Vascular responses of the extremities to transdermal application of vasoactive agents in Caucasian and African descent individuals. Eur J Appl Physiol, 115(8), 1801-11.

Matthews, D. R., Hosker, J. P., Rudenski, A. S., Naylor, B. A., Treacher, D. F. \& Turner, R. C. (1985) Homeostasis model assessment: insulin resistance and beta-cell function from fasting plasma glucose and insulin concentrations in man. Diabetologia, 28(7), 412-9.

Meigs, J. B., Hu, F. B., Rifai, N. \& Manson, J. E. (2004) Biomarkers of endothelial dysfunction and risk of type 2 diabetes mellitus. Jama, 291(16), 1978-86.

Meigs, J. B., O'Donnell C, J., Tofler, G. H., Benjamin, E. J., Fox, C. S., Lipinska, I., Nathan, D. M., Sullivan, L. M., D'Agostino, R. B. \& Wilson, P. W. (2006) Hemostatic markers of endothelial dysfunction and risk of incident type 2 diabetes: the Framingham Offspring Study. Diabetes, 55(2), 530-7.

Mellergard, P., Aneman, O., Sjögren, F., Pettersson, P. \& Hillman, J. (2008) Changes in extracellular concentrations of some cytokines, chemokines, and neurotrophic factors after insertion of intracerebral microdialysis catheters in neurosurgical patients, Neurosurgery. United States, 151-7; discussion 157-8. 
Minson, C. T. (2010) Thermal provocation to evaluate microvascular reactivity in human skin. J Appl Physiol (1985), 109(4), 1239-46.

Minson, C. T., Berry, L. T. \& Joyner, M. J. (2001) Nitric oxide and neurally mediated regulation of skin blood flow during local heating. J Appl Physiol (1985), 91(4), 161926.

Montero, D., Walther, G., Perez-Martin, A., Santamaria, C., Roche, E., Mercier, C. \& Vinet, A. (2014) Decreased microvascular myogenic response to insulin in severely obese adolescents. Clin Hemorheol Microcirc, 57(1), 23-32.

Morris, S. J. \& Shore, A. C. (1996) Skin blood flow responses to the iontophoresis of acetylcholine and sodium nitroprusside in man: possible mechanisms. J Physiol, 496 ( Pt 2), 531-42.

Morris, S. J., Shore, A. C. \& Tooke, J. E. (1995) Responses of the skin microcirculation to acetylcholine and sodium nitroprusside in patients with NIDDM. Diabetologia, 38(11), 1337-44.

Mudaliar, S. R., Lindberg, F. A., Joyce, M., Beerdsen, P., Strange, P., Lin, A. \& Henry, R. R. (1999) Insulin aspart (B28 asp-insulin): a fast-acting analog of human insulin: absorption kinetics and action profile compared with regular human insulin in healthy nondiabetic subjects. Diabetes Care, 22(9), 1501-6.

Muniyappa, R., Iantorno, M. \& Quon, M. J. (2008) An integrated view of insulin resistance and endothelial dysfunction. Endocrinol Metab Clin North Am, 37(3), 685711 , ix-X.

Myers, P. R., Banitt, P. F., Guerra, R., Jr. \& Harrison, D. G. (1991) Role of the endothelium in modulation of the acetylcholine vasoconstrictor response in porcine coronary microvessels. Cardiovasc Res, 25(2), 129-37.

Noguchi, K., Matsuzaki, T., Sakanashi, M., Hamadate, N., Uchida, T., Kina-Tanada, M., Kubota, H., Nakasone, J., Ueda, S., Masuzaki, H., Ishiuchi, S., Ohya, Y. \& Tsutsui, M. (2015) Effect of caffeine contained in a cup of coffee on microvascular function in healthy subjects. $J$ Pharmacol Sci, 127(2), 217-22.

Noon, J. P., Walker, B. R., Hand, M. F. \& Webb, D. J. (1998) Studies with iontophoretic administration of drugs to human dermal vessels in vivo: cholinergic vasodilatation is mediated by dilator prostanoids rather than nitric oxide. Br J Clin Pharmacol, 45(6), 545-50.

O'Doherty, J., Henricson, J., Anderson, C., Leahy, M. J., Nilsson, G. E. \& Sjoberg, F. (2007) Sub-epidermal imaging using polarized light spectroscopy for assessment of skin microcirculation. Skin Res Technol, 13(4), 472-84.

Panazzolo, D. G., Silva, L. H., Cyrino, F. Z., Sicuro, F. L., Kraemer-Aguiar, L. G. \& Bouskela, E. (2013) Gender differences in microcirculation: observation using the hamster cheek pouch. Clinics (Sao Paulo), 68(12), 1537-42.

Petersen, L. J., Zacho, H. D., Lyngholm, A. M. \& Arendt-Nielsen, L. (2010) Tissue viability imaging for assessment of pharmacologically induced vasodilation and vasoconstriction in human skin. Microvasc Res, 80(3), 499-504. 
Pfeiffer, S., Leopold, E., Schmidt, K., Brunner, F. \& Mayer, B. (1996) Inhibition of nitric oxide synthesis by NG-nitro-L-arginine methyl ester (L-NAME): requirement for bioactivation to the free acid, NG-nitro-L-arginine. Br J Pharmacol, 118(6), 1433-40.

Puissant, C., Abraham, P., Durand, S., Humeau-Heurtier, A., Faure, S., Leftheriotis, G., Rousseau, P. \& Mahe, G. (2013) Reproducibility of non-invasive assessment of skin endothelial function using laser Doppler flowmetry and laser speckle contrast imaging. PLoS One, 8(4), e61320.

Rajamand, N., Ungerstedt, U. \& Brismar, K. (2005) Subcutaneous microdialysis before and after an oral glucose tolerance test: a method to determine insulin resistance in the subcutaneous adipose tissue in diabetes mellitus. Diabetes Obes Metab, 7(5), 525-35.

Rosdahl, H., Hamrin, K., Ungerstedt, U. \& Henriksson, J. (1998) Metabolite levels in human skeletal muscle and adipose tissue studied with microdialysis at low perfusion flow. Am J Physiol, 274(5 Pt 1), E936-45.

Rosdahl, H., Hamrin, K., Ungerstedt, U. \& Henriksson, J. (2000) A microdialysis method for the in situ investigation of the action of large peptide molecules in human skeletal muscle: detection of local metabolic effects of insulin. Int J Biol Macromol, 28(1), 69-73.

Rossi, M., Carpi, A., Galetta, F., Franzoni, F. \& Santoro, G. (2008) Skin vasomotion investigation: a useful tool for clinical evaluation of microvascular endothelial function? Biomed Pharmacother, 62(8), 541-5.

Rossi, M., Cupisti, A., Mariani, S., Santoro, G. \& Pentimone, F. (2002) Endotheliumdependent and endothelium-independent skin vasoreactivity in the elderly. Aging Clin Exp Res, 14(5), 343-6.

Rossi, M., Maurizio, S. \& Carpi, A. (2005a) Skin blood flowmotion response to insulin iontophoresis in normal subjects. Microvasc Res, 70(1-2), 17-22.

Rossi, M., Nannipieri, M., Anselmino, M., Pesce, M., Muscelli, E., Santoro, G. \& Ferrannini, E. (2011) Skin vasodilator function and vasomotion in patients with morbid obesity: effects of gastric bypass surgery. Obes Surg, 21(1), 87-94.

Rossi, M., Santoro, G., Ricco, R., Pentimone, F. \& Carpi, A. (2005b) Effect of chronic aerobic exercise on cutaneous microcirculatory flow response to insulin iontophoresis and to ischemia in elderly males. Int J Sports Med, 26(7), 558-62.

Roustit, M., Millet, C., Blaise, S., Dufournet, B. \& Cracowski, J. L. (2010) Excellent reproducibility of laser speckle contrast imaging to assess skin microvascular reactivity. Microvasc Res, 80(3), 505-11.

Samuelsson, A., Farnebo, S., Magnusson, B., Anderson, C., Tesselaar, E., Zettersten, E. \& Sjoberg, F. (2012) Implications for burn shock resuscitation of a new in vivo human vascular microdosing technique (microdialysis) for dermal administration of noradrenaline. Burns, 38(7), 975-83.

Sandqvist, M., Strindberg, L., Schmelz, M., Lonnroth, P. \& Jansson, P. A. (2011) Impaired delivery of insulin to adipose tissue and skeletal muscle in obese women with postprandial hyperglycemia. J Clin Endocrinol Metab, 96(8), E1320-4. 
Serne, E. H., de Jongh, R. T., Eringa, E. C., RG, I. J. \& Stehouwer, C. D. (2007) Microvascular dysfunction: a potential pathophysiological role in the metabolic syndrome. Hypertension, 50(1), 204-11.

Serne, E. H., RG, I. J., Gans, R. O., Nijveldt, R., De Vries, G., Evertz, R., Donker, A. J. \& Stehouwer, C. D. (2002) Direct evidence for insulin-induced capillary recruitment in skin of healthy subjects during physiological hyperinsulinemia. Diabetes, 51(5), 1515-22.

Serne, E. H., Stehouwer, C. D., ter Maaten, J. C., ter Wee, P. M., Rauwerda, J. A., Donker, A. J. \& Gans, R. O. (1999) Microvascular function relates to insulin sensitivity and blood pressure in normal subjects. Circulation, 99(7), 896-902.

Sjögren, F. \& Anderson, C. (2009) Sterile trauma to normal human dermis invariably induces IL1beta, IL6 and IL8 in an innate response to "danger". Acta Derm Venereol, 89(5), 459-65.

Tee, G. B., Rasool, A. H., Halim, A. S. \& Rahman, A. R. (2004) Dependence of human forearm skin postocclusive reactive hyperemia on occlusion time. J Pharmacol Toxicol Methods, 50(1), 73-8.

Tesselaar, E., Schiffer, A., Widdershoven, J., Broers, H., Hendriks, E., Luijten, K. \& Creusen, J. (2012) Effect of cardiac resynchronization therapy on endotheliumdependent vasodilatation in the cutaneous microvasculature. Pacing Clin Electrophysiol, 35(4), 377-84.

Tesselaar, E. \& Sjoberg, F. (2011) Transdermal iontophoresis as an in-vivo technique for studying microvascular physiology. Microvasc Res, 81(1), 88-96.

Thennadil, S. N., Rennert, J. L., Wenzel, B. J., Hazen, K. H., Ruchti, T. L. \& Block, M. B. (2001) Comparison of glucose concentration in interstitial fluid, and capillary and venous blood during rapid changes in blood glucose levels. Diabetes Technol Ther, 3(3), 357-65.

Thompson-Torgerson, C. S., Holowatz, L. A., Flavahan, N. A. \& Kenney, W. L. (2007) Cold-induced cutaneous vasoconstriction is mediated by Rho kinase in vivo in human skin. Am J Physiol Heart Circ Physiol, 292(4), H1700-5.

Tur, E., Tur, M., Maibach, H. I. \& Guy, R. H. (1983) Basal perfusion of the cutaneous microcirculation: measurements as a function of anatomic position. J Invest Dermatol, 81(5), 442-6.

Turner, J., Belch, J. J. \& Khan, F. (2008) Current concepts in assessment of microvascular endothelial function using laser Doppler imaging and iontophoresis. Trends Cardiovasc Med, 18(4), 109-16.

Turner, N. G. \& Guy, R. H. (1997) Iontophoretic transport pathways: dependence on penetrant physicochemical properties. J Pharm Sci, 86(12), 1385-9.

Tziomalos, K., Athyros, V.G., Karagiannis, A. \& Mikhailidis, D.P. (2010) Endothelial dysfunction in metabolic syndrome: prevalence, pathogenesis and man- agement. Nutr Metab Cardiovasc Dis. 20:140-146. 
Ungerstedt, U. (1991) Microdialysis--principles and applications for studies in animals and man. $J$ Intern Med, 230(4), 365-73.

Ungerstedt, U. \& Pycock, C. (1974) Functional correlates of dopamine neurotransmission. Bull Schweiz Akad Med Wiss, 30(1-3), 44-55.

Vanhoutte, P. M. \& Tang, E. H. (2008) Endothelium-dependent contractions: when a good guy turns bad! J Physiol, 586(22), 5295-304.

Vincent, M. A., Clerk, L. H., Lindner, J. R., Klibanov, A. L., Clark, M. G., Rattigan, S. $\&$ Barrett, E. J. (2004) Microvascular recruitment is an early insulin effect that regulates skeletal muscle glucose uptake in vivo. Diabetes, 53(6), 1418-23.

Vinik, A. I., Erbas, T., Park, T. S., Stansberry, K. B., Scanelli, J. A. \& Pittenger, G. L. (2001) Dermal neurovascular dysfunction in type 2 diabetes. Diabetes Care, 24(8), 1468-75.

Walloe, L. (2016) Arterio-venous anastomoses in the human skin and their role in temperature control. Temperature (Austin), 3(1), 92-103.

Waterhouse, N., Finney, R., Griffiths, R. W. \& Richardson, R. B. (1986) Observations on dermal blood flow as reflected by technetium-99m pertechnetate clearance. $\mathrm{Br} J$ Plast Surg, 39(3), 312-20.

World Health Organization \& International Diabetes Federation. (2006) Definition and diagnosis of diabetes mellitus and intermediate hyperglycaemia, WHO Document Production Services, Geneva, Switzerland. ISBN 978924159493 6. Page 1-3, 29-32.

Wong, B. J., Wilkins, B. W., Holowatz, L. A. \& Minson, C. T. (2003) Nitric oxide synthase inhibition does not alter the reactive hyperemic response in the cutaneous circulation. J Appl Physiol (1985), 95(2), 504-10.

Yang, Y. J., Hope, I. D., Ader, M. \& Bergman, R. N. (1994) Importance of transcapillary insulin transport to dynamics of insulin action after intravenous glucose. Am J Physiol, 266(1 Pt 1), E17-25.

Østerberg, O., Erichsen, L., Ingwersen, S. H., Plum, A., Poulsen, H. E. \& Vicini, P. (2003) Pharmacokinetic and pharmacodynamic properties of insulin aspart and human insulin. J Pharmacokinet Pharmacodyn, 30(3), 221-35. 



\section{Papers}

The articles associated with this thesis have been removed for copyright reasons. For more details about these see:

http://urn.kb.se/resolve?urn=urn:nbn:se:liu:diva- 132167 